\title{
EFFECT OF PHOSPHATE, FLUORIDE, AND NITRATE ON GIBBSITE DISSOLUTION RATE AND SOLUBILITY
}

\section{L. Herting}

Washington River Protection Solutions LLC

Date Published

January 2014

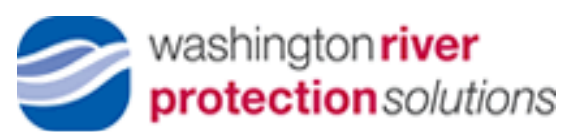

P.O. Box 850

Richland, Washington

Contractor for the U.S. Department of Energy

Office of River Protection under Contract DE-AC27-08RV14800 
TRADEMARK DISCLAIMER

Reference herein to any specific commercial product, process,

or service by trade name, trademark, manufacturer, or

otherwise, does not necessarily constitute or imply its

endorsement, recommendation, or favoring by the United

States Government or any agency thereof or its contractors or subcontractors.

This report has been reproduced from the best available copy.

Printed in the United States of America 


\section{Contents}

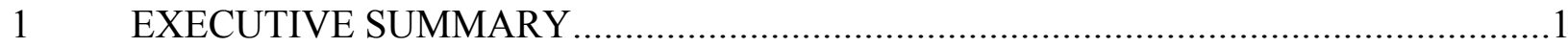

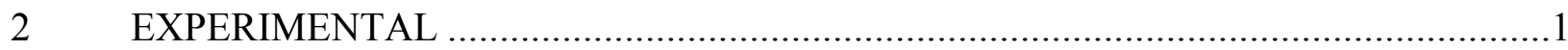

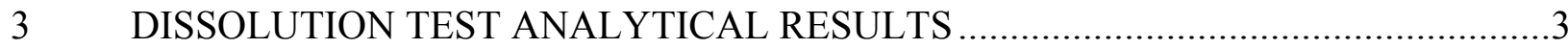

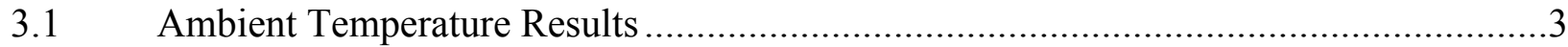

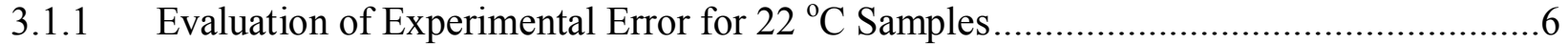

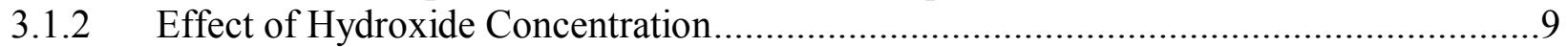

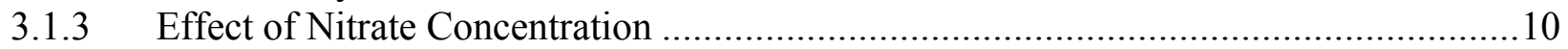

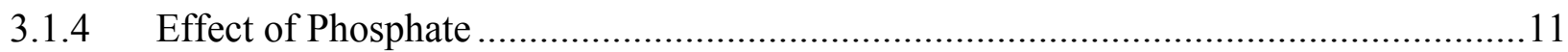

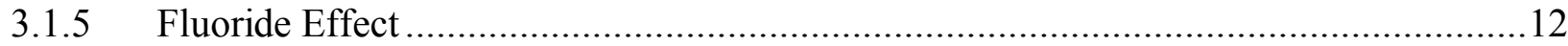

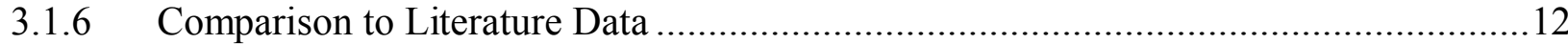

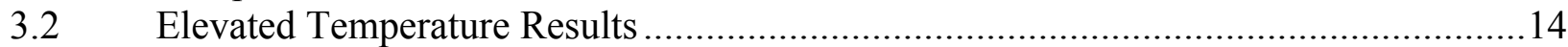

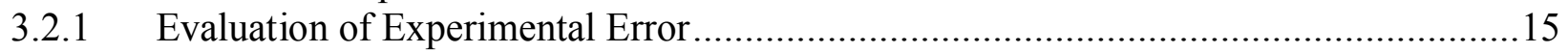

3.2.2 Effect of Hydroxide Concentration.......................................................................

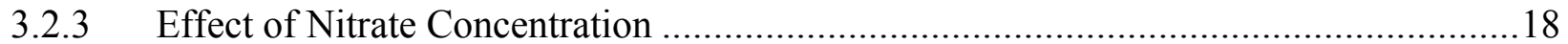

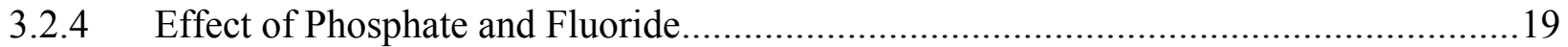

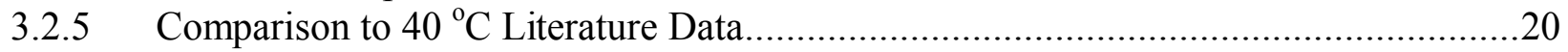

4 COMPARISON TO COMPUTER MODEL PREDICTIONS …...................................22

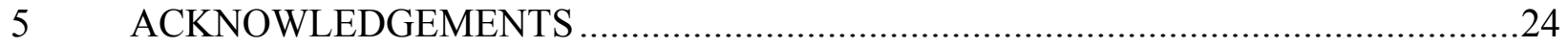

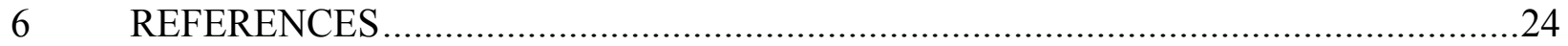

\section{List of Figures}

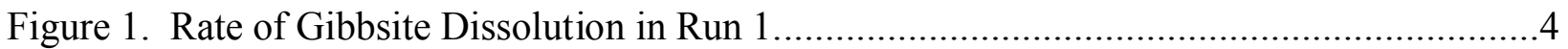

Figure 2. Reproducibility of Ambient Temperature Runs. .......................................................

Figure 3. Effect of Hydroxide on Gibbsite Dissolution at Ambient Temperature .......................9

Figure 4. Effect of Nitrate on Gibbsite Dissolution at Ambient Temperature. ............................10

Figure 5. Effect of Phosphate on Gibbsite Dissolution at Ambient Temperature........................11

Figure 6. Effect of Fluoride/Phosphate on Gibbsite Dissolution at Ambient Temperature.........12

Figure 7. Comparison of Sample Data $\left(22^{\circ} \mathrm{C}\right)$ to Literature Data $\left(25^{\circ} \mathrm{C}\right)$ for Gibbsite Solubility.

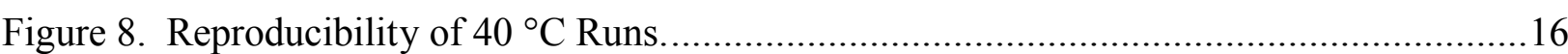

Figure 9. Effect of Hydroxide on Gibbsite Dissolution at $40^{\circ} \mathrm{C}$............................................17

Figure 10. Effect of Nitrate on Gibbsite Dissolution at $40^{\circ} \mathrm{C}$.................................................18

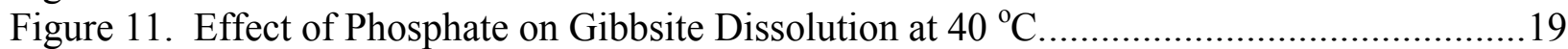

Figure 12. Effect of Fluoride/Phosphate on Gibbsite Dissolution at $40{ }^{\circ} \mathrm{C}$................................20

Figure 13. Comparison of Sample Data $\left(40{ }^{\circ} \mathrm{C}\right)$ to Literature Data $\left(40{ }^{\circ} \mathrm{C}\right)$ for Gibbsite

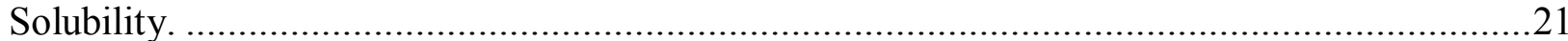

Figure 14. Comparison of Experimental Data with Environmental Simulation Program

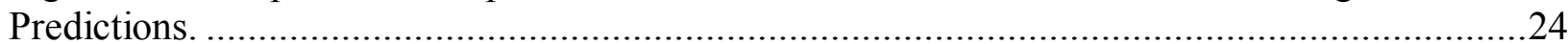




\section{List of Tables}

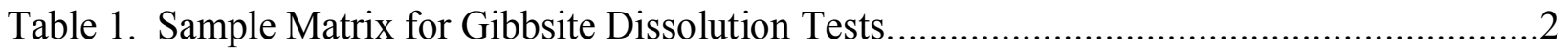

Table 2. Spreadsheet Used to Calculate Parameters for Equation 3-2, Run 1 . ............................5

Table 3. Concentrations (in molality) at Final Sampling Point for $22{ }^{\circ} \mathrm{C}$ Samples......................6

Table 4. Concentration (in molality) of Phosphate in Ambient Temperature Samples. ...............12

Table 5. Concentrations (in molality) at Final Sampling Point for $40^{\circ} \mathrm{C}$ Samples.......................14

Table 6. Concentrations (in molality) of Phosphate in $40^{\circ} \mathrm{C}$ Samples......................................20

Table 7. Comparison of Experimental Data ${ }^{1}\left(\mathrm{Al}_{\text {equil }}\right)$ with Environmental Simulation Program-

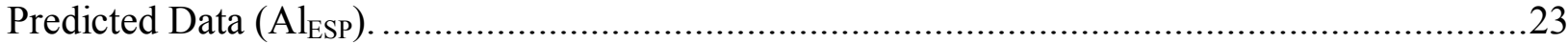

\section{List of Terms}

\section{Acronyms and Abbreviations}

AS

ESP

ICP-AES
Analyzer Studio

Environmental Simulation Program

inductively coupled plasma-atomic emission spectroscopy

\section{Units}

$\begin{array}{ll}{ }^{\circ} \mathrm{C} & \text { degrees Celsius } \\ \mathrm{g} & \text { gram } \\ \mathrm{Kg} & \text { kilogram } \\ \mu \mathrm{g} & \text { microgram } \\ \mathrm{L} & \text { liter } \\ \mathrm{m} & \text { molal } \\ \mathrm{M} & \text { molar (moles per liter) } \\ \mathrm{mL} & \text { milliliter } \\ \mathrm{mol} & \text { mole }\end{array}$




\section{EXECUTIVE SUMMARY}

Laboratory tests have been completed with simulated tank waste samples to investigate the effects of phosphate, fluoride, and nitrate on the dissolution rate and equilibrium solubility of gibbsite in sodium hydroxide solution at 22 and $40{ }^{\circ} \mathrm{C}$. Results are compared to relevant literature data and to computer model predictions.

The presence of sodium nitrate $(3 \mathrm{M})$ caused a reduction in the rate of gibbsite dissolution in $\mathrm{NaOH}$, but a modest increase in the equilibrium solubility of aluminum. The increase in solubility was not as large, though, as the increase predicted by the computer model.

The presence of phosphate, either as sodium phosphate or sodium fluoride phosphate, had a negligible effect on the rate of gibbsite dissolution, but caused a slight increase in aluminum solubility. The magnitude of the increased solubility, relative to the increase caused by sodium nitrate, suggests that the increase is due to ionic strength (or water activity) effects, rather than being associated with the specific ion involved. The computer model predicted that phosphate would cause a slight decrease in aluminum solubility, suggesting some $\mathrm{Al}_{-} \mathrm{PO}_{4}$ interaction. No evidence was found of such an interaction.

\section{EXPERIMENTAL}

Gibbsite dissolution tests were performed at ambient temperature $\left(22 \pm 1{ }^{\circ} \mathrm{C}\right)$ and at $40 \pm 1{ }^{\circ} \mathrm{C}$. Variables were $\mathrm{OH}^{-}(1.0,2.0$, and $3.0 \mathrm{M}), \mathrm{PO}_{4}{ }^{3-}$ (absent or saturated as sodium phosphate or fluoride phosphate), $\mathrm{F}^{-}$(absent or saturated as sodium fluoride phosphate), and $\mathrm{NO}_{3}{ }^{-}$(absent or $3.0 \mathrm{M})$. The chemicals used were:

- Gibbsite, $\mathrm{Al}(\mathrm{OH})_{3}$, Almatis hydrated alumina $\mathrm{C} 33$

- Sodium hydroxide, $\mathrm{NaOH}, \mathrm{EMD}, \mathrm{ACS}$ grade

- Sodium phosphate, $\mathrm{Na}_{3} \mathrm{PO}_{4} \bullet 12 \mathrm{H}_{2} \mathrm{O} \bullet 1 / 4 \mathrm{NaOH}$, J. T. Baker, ACS reagent grade

- Sodium fluoride, $\mathrm{NaF}$, Sigma-Aldrich, ACS reagent grade

- Sodium nitrate, $\mathrm{NaNO}_{3}$, Sigma-Aldrich, ACS reagent grade.

Samples were taken periodically, filtered, and analyzed for density, selected elements (Na, Al, P) by inductively coupled plasma-atomic emission spectroscopy (ICP-AES), and free hydroxide by titration.

Initially, twelve samples were prepared at each temperature, labeled ALP2-1 - ALP2-12 for the ambient-temperature samples and ALP2-21 - ALP2-32 for the $40{ }^{\circ} \mathrm{C}$ samples. After preliminary analytical results showed that the samples were not coming to equilibrium within the original timeframe of the test, additional samples (ALP2-55 - APL-62 at ambient temperature, 
ALP2-41 - ALP2-47 at $40{ }^{\circ} \mathrm{C}$ ) were prepared to equilibrate over longer test periods. The final parametric matrix is shown in Table 1.

Consistency of data trends was used in place of sample duplicates to assess data quality. In addition, several samples contained zero phosphate, fluoride, and nitrate, so results could be compared to literature data for the pure-component phase diagram.

Table 1. Sample Matrix for Gibbsite Dissolution Tests.

\begin{tabular}{|c|c|c|c|c|c|}
\hline \multicolumn{2}{|c|}{ Sample Number } & \multicolumn{4}{|c|}{ Concentration, Molarity } \\
\hline $\mathbf{2 2}^{\mathbf{}} \mathbf{C}$ & $\mathbf{4 0}{ }^{\mathbf{}} \mathbf{C}$ & $\mathbf{O H}^{-}$ & PO $^{{ }^{-}}$ & $\mathbf{F}^{-}$ & $\mathbf{N O}^{-}$ \\
\hline ALP2-1 & ALP2-21/41 & 1.0 & Saturated & Saturated & Absent \\
\hline ALP2-2 & ALP2-22/42 & 1.0 & Saturated & Absent & Absent \\
\hline ALP2-3 & ALP2-23/43 & 1.0 & Absent & Absent & Absent \\
\hline ALP2-4 & ALP2-24/44 & 1.0 & Absent & Absent & 3.0 \\
\hline ALP2-5/55 & ALP2-25/45 & 2.0 & Saturated & Saturated & Absent \\
\hline ALP2-6/56 & ALP2-26/46 & 2.0 & Saturated & Absent & Absent \\
\hline ALP2-7/57 & ALP2-27/47 & 2.0 & Absent & Absent & Absent \\
\hline ALP2-8/58 & ALP2-28 & 2.0 & Absent & Absent & 3.0 \\
\hline ALP2-9/59 & ALP2-29 & 3.0 & Saturated & Saturated & Absent \\
\hline ALP2-10/60 & ALP2-30 & 3.0 & Saturated & Absent & Absent \\
\hline ALP2-11/61 & ALP2-31 & 3.0 & Absent & Absent & Absent \\
\hline ALP2-12/62 & ALP2-32 & 3.0 & Absent & Absent & 3.0 \\
\hline
\end{tabular}

Ambient-temperature samples, which were approximately $80-100 \mathrm{~mL}$ in volume, were kept in 125-mL polyethylene bottles on a rotator which tumbled the bottles continually. Slurries were sampled periodically by (a) recording the temperature of the slurry with a standardized thermometer, (b) allowing the slurry to settle briefly, (c) filtering a portion of the slurry through a syringe filter, (d) filling a 10-mL volumetric flask to determine the density of the filtrate, and (e) transferring the liquid from the volumetric flask to a sample vial for submission to the analytical laboratory for ICP-AES and free $\mathrm{OH}^{-}$analyses.

Elevated temperature samples were kept in polyethylene bottles in a $40{ }^{\circ} \mathrm{C}$ shaker bath. Slurries were sampled periodically by the same method as the ambient-temperature slurries except that the liquid in the $10-\mathrm{mL}$ volumetric flask was transferred quantitatively with water to a $25-\mathrm{mL}$ flask to prevent precipitation of the sample when it cooled to ambient temperature. Densities of the diluted and undiluted liquids were recorded.

For the initial set of samples, the ambient temperature slurries $(1-12)$ were sampled weekly for 5 weeks, and the $40{ }^{\circ} \mathrm{C}$ samples $(21-27)$ were sampled at $1,2,3,4$, and 7 days. For the followup set, the ambient temperature slurries $(55-62)$ were sampled once every two weeks for 10 weeks, and the $40{ }^{\circ} \mathrm{C}$ samples $(28-32$ and $41-47)$ were sampled at 1,4 or $5,7,9$ or 10 , and 14 days. 


\section{DISSOLUTION TEST ANALYTICAL RESULTS}

Periodic samples were analyzed for density $(\mathrm{g} / \mathrm{mL})$ and concentrations $(\mu \mathrm{g} / \mathrm{mL})$ of $\mathrm{Al}, \mathrm{Na}, \mathrm{P}$, and free $\mathrm{OH}^{-}$. Results are shown in Appendix A. Conversion of $\mu \mathrm{g} / \mathrm{mL}$ concentrations to molar (M) concentrations (Appendix A) is a simple matter of converting units and dividing by the formula weight, as shown by the example in Equation 3-1:

$$
1270 \mu \mathrm{g} / \mathrm{mL} \mathrm{Al} *(1 \mathrm{~g} / 1 \mathrm{E6} \mu \mathrm{g}) *(1000 \mathrm{~mL} / 1 \mathrm{~L}) *(1 \mathrm{~mol} / 27.0 \mathrm{~g})=0.047 \mathrm{M} \mathrm{Al}
$$

Conversion of molar concentrations to molal $(\mathrm{m})$ concentrations requires information about the water content of the samples, which was determined by calculation (which is probably at least as accurate, for these samples, as percent water analytical results would be).

Step 1 of the molality conversion is to calculate the total mass of the liquid phase in each bottle, which is the sum of the water added plus the water-soluble portions of the chemicals that were added. For all of these samples, the $\mathrm{NaOH}$ and $\mathrm{NaNO}_{3}$ are assumed to be completely soluble. For the ambient-temperature samples, the $\mathrm{Al}(\mathrm{OH})_{3}, \mathrm{Na}_{3} \mathrm{PO}_{4} \bullet 12 \mathrm{H}_{2} \mathrm{O} \bullet 1 / 4 \mathrm{NaOH}$, and $\mathrm{NaF}$ are assumed to be $25 \%$ soluble. For the $40{ }^{\circ} \mathrm{C}$ samples, the $\mathrm{Al}(\mathrm{OH})_{3}, \mathrm{Na}_{3} \mathrm{PO}_{4} \bullet 12 \mathrm{H}_{2} \mathrm{O} \cdot 1 / 4 \mathrm{NaOH}$, and $\mathrm{NaF}$ are assumed to be $50 \%$ soluble. (Comparison of observed liquid phase molalities with the corresponding theoretical molalities based on $100 \%$ dissolution of all salts shows that these $25 \%$ and $50 \%$ dissolution estimates are reasonable.)

Step 2 of the molality conversion is to calculate the total liquid phase volume, which is equal to the total liquid phase mass from Step 1 divided by the density measured for the individual samples. Step 3 is to calculate the total mass of $\mathrm{H}_{2} \mathrm{O}$ in each bottle, which is set equal to the mass of $\mathrm{H}_{2} \mathrm{O}$ added as $\mathrm{H}_{2} \mathrm{O}$ plus the mass of $\mathrm{H}_{2} \mathrm{O}$ derived from dissolution of $25 \%$ (or $50 \%$ ) of the added $\mathrm{Na}_{3} \mathrm{PO}_{4} \cdot 12 \mathrm{H}_{2} \mathrm{O} \cdot 1 / 4 \mathrm{NaOH}$. Step 4 is to divide the mass of $\mathrm{H}_{2} \mathrm{O}$ from Step 3 by the volume of the liquid phase from Step 2 to give $\mathrm{kg} \mathrm{H}_{2} \mathrm{O}$ per liter. Step 5, the final step, is to divide the molarity $(\mathrm{mol} / \mathrm{L})$ by the factor from Step $4\left(\mathrm{~kg} \mathrm{H}_{2} \mathrm{O} / \mathrm{L}\right)$ to give molality $\left(\mathrm{mol} / \mathrm{kg} \mathrm{H}_{2} \mathrm{O}\right)$.

Tables in Appendix A show concentrations in all 3 units $(\mu \mathrm{g} / \mathrm{mL}$, molarity, molality) for all subsamples as a function of time.

\subsection{AMBIENT TEMPERATURE RESULTS}

Slurry temperatures recorded during the ambient-temperature equilibration period averaged $22{ }^{\circ} \mathrm{C}$. The highest temperature recorded for any individual sample was $22.9{ }^{\circ} \mathrm{C}$ and the lowest was $20.8^{\circ} \mathrm{C}$.

Runs $1-12$ were conducted at ambient temperature with samples taken at 1-week intervals for a total of 5 weeks. Analytical results are shown in Tables A-1 through A-3 in Appendix A. Results show that none of the samples reached equilibrium (i.e., constant Al concentration). 
Runs 5-12 were repeated as Runs 55-62 with sampling every 2 weeks for a total of 10 weeks. Analytical results are shown in Table A-4 through A-6 in Appendix A. Several of these re-run samples still had not reached equilibrium after 10 weeks.

Figure 1 shows a plot of Al molality as a function of time for Run 1 (1.3 m hydroxide, saturated in fluoride and phosphate). Corresponding plots for other runs are shown in Appendix B. None of the plots fit a "standard" kinetic pattern (i.e., none of the plots fit zero-order, first-order, or second-order kinetics). However, because the $\mathrm{Al}$ concentration begins at zero molal at zero time, and reaches some constant value at equilibrium (at infinite time), the data can be fit using an asymptotic function like Equation 3-2

$$
y=a x /(b+x)
$$

where $y=\mathrm{Al}$ molality, $x=$ time (weeks for ambient temperature runs, days for $40{ }^{\circ} \mathrm{C}$ runs), and $a$ and $b$ are parameters that are adjusted to optimize the fit to the data points. Parameter $a$ is also equal to the value of $y$ at infinite time, and therefore represents the equilibrium concentration of Al predicted by the equation. The resulting equation for Run 1 is shown as the solid line labeled "Fit" in Figure 1.

Figure 1. Rate of Gibbsite Dissolution in Run 1.

$\left(22{ }^{\circ} \mathrm{C}, 1.3 \mathrm{~m} \mathrm{NaOH}\right.$, saturated in fluoride and phosphate, no nitrate)

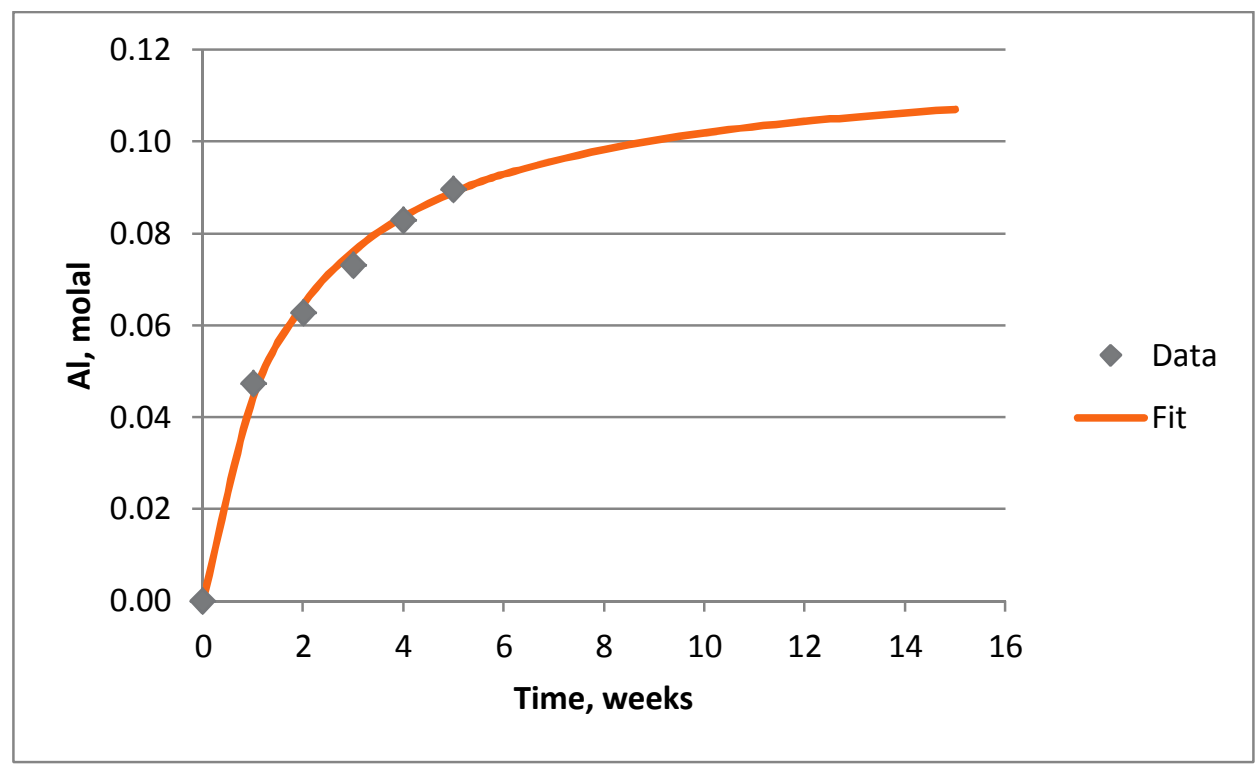

The "Solver" function in Microsoft Excel was used to optimize the values of the parameters in Equation 3-2. The process is shown in Table 2, which represents an Excel spreadsheet. Column A contains the sample time in weeks $(x)$. Column B contains the measured Al molality (y). Column $\mathrm{C}$ contains, initially, a reasonable-guess value for parameter $a$, the equilibrium concentration of Al. Column D contains, initially, a reasonable-guess value for parameter $b$, which determines the shape of the curve. Column E contains the $y$ result of Equation 3-2, the 
predicted Al concentration at time $x$. Column $\mathrm{F}$ contains the square of the difference between the measured and predicted Al concentrations (Columns B and E). Cell F8 contains the sum of the squared differences in Column F, with added weight placed on the final data point (cell F7). The Solver is then used to minimize the value of cell F8 using cells C2 and D2 as input variables. The resulting values are entered into cells F8, C2, and D2. This process was repeated for all of the runs in this study.

Table 2. Spreadsheet Used to Calculate Parameters for Equation 3-2, Run 1.

\begin{tabular}{|c|c|c|c|c|c|c|}
\hline & $\mathbf{A}$ & B & $\mathbf{C}$ & D & $\mathbf{E}$ & $\mathbf{F}$ \\
\hline 1 & $\mathrm{x}=$ time & $\mathrm{y}=\mathrm{Al} l_{\text {measured }}$ & 'a' & 'b' & $y=a x /(b+x)$ & $(B-E)^{2}$ \\
\hline 2 & 0 & 0 & 0.119 & 1.695 & 0 & 0 \\
\hline 3 & 1 & 0.047 & -- & -- & 0.044 & $9.99 \mathrm{E}-6$ \\
\hline 4 & 2 & 0.063 & -- & -- & 0.065 & $3.36 \mathrm{E}-6$ \\
\hline 5 & 3 & 0.073 & -- & -- & 0.076 & $9.20 \mathrm{E}-6$ \\
\hline 6 & 4 & 0.083 & -- & -- & 0.084 & $7.86 \mathrm{E}-7$ \\
\hline 7 & 5 & 0.090 & -- & -- & 0.089 & $2.82 \mathrm{E}-7$ \\
\hline 8 & \multicolumn{5}{|c|}{ SUM(F3..F6)+5*F7 = } & $2.50 \mathrm{E}-5$ \\
\hline
\end{tabular}

It is clear from the plots in Appendix B that the gibbsite dissolution rate is not a perfect fit to the asymptotic function of Equation 3-2. In nearly all cases, there appear to be two distinct regions a brief initial period of very rapid dissolution, followed by an extended period of much slower dissolution at a nearly linear rate. Nevertheless, the asymptotic function does appear to provide a reasonable estimate of the equilibrium $\mathrm{Al}$ concentration in most runs. These predicted values are collected in Table 3 along with the measured (or calculated) concentrations of the other solution components at the final sampling point $(t=5$ weeks or $t=10$ weeks $)$ for all of the ambienttemperature runs. 
Table 3. Concentrations (in molality) at Final Sampling Point for $22{ }^{\circ} \mathrm{C}$ Samples.

\begin{tabular}{|c|c|c|c|c|c|c|c|c|}
\hline Run & $\begin{array}{c}\text { Time, } \\
\text { weeks }\end{array}$ & $\mathbf{N a}^{+}$ & $\mathbf{P O}_{\mathbf{4}}{ }^{3-\mathbf{a}}$ & $\mathbf{F}^{-}$ & $\mathbf{N O}_{\mathbf{3}}{ }^{-\mathbf{c}}$ & $\mathbf{O H}^{-}$ & $\mathbf{A I}_{\text {measured }}$ & $\mathbf{A l}_{\text {equil }}{ }^{{ }^{\mathbf{b}}}$ \\
\hline 1 & 5 & 1.87 & 0.107 & 0.054 & 0.00 & 1.30 & 0.090 & 0.119 \\
\hline 2 & 5 & 1.89 & 0.145 & 0.000 & 0.00 & 1.24 & 0.090 & 0.133 \\
\hline 3 & 5 & 1.47 & 0.000 & 0.000 & 0.00 & 1.30 & 0.075 & 0.100 \\
\hline 4 & 5 & 5.39 & 0.000 & 0.000 & 3.76 & 1.30 & 0.072 & 0.106 \\
\hline 5 & 5 & 3.15 & 0.058 & 0.029 & 0.00 & 2.53 & 0.201 & 0.249 \\
\hline 55 & 10 & 3.04 & 0.050 & 0.025 & 0.00 & 2.50 & 0.205 & 0.225 \\
\hline 6 & 5 & 3.06 & 0.060 & 0.000 & 0.00 & 2.48 & 0.200 & 0.255 \\
\hline 56 & 10 & 2.94 & 0.052 & 0.000 & 0.00 & 2.45 & 0.201 & 0.220 \\
\hline 7 & 5 & 2.94 & 0.000 & 0.000 & 0.00 & 2.54 & 0.178 & 0.213 \\
\hline 57 & 10 & 2.84 & 0.000 & 0.000 & 0.00 & 2.51 & 0.188 & 0.215 \\
\hline 8 & 5 & 6.97 & 0.000 & 0.000 & 3.75 & 2.53 & 0.186 & 0.237 \\
\hline 58 & 10 & 6.75 & 0.000 & 0.000 & 3.75 & 2.52 & 0.204 & 0.259 \\
\hline 9 & 5 & 4.45 & 0.034 & 0.017 & 0.00 & 3.76 & 0.321 & 0.376 \\
\hline 59 & 10 & 4.33 & 0.030 & 0.015 & 0.00 & 3.67 & 0.339 & 0.357 \\
\hline 10 & 5 & 4.33 & 0.033 & 0.000 & 0.00 & 3.75 & 0.311 & 0.376 \\
\hline 60 & 10 & 4.28 & 0.030 & 0.000 & 0.00 & 3.73 & 0.338 & 0.356 \\
\hline 11 & 5 & 4.26 & 0.000 & 0.000 & 0.00 & 3.76 & 0.319 & 0.330 \\
\hline 61 & 10 & 4.20 & 0.000 & 0.000 & 0.00 & 3.71 & 0.323 & 0.334 \\
\hline 12 & 5 & 8.11 & 0.000 & 0.000 & 3.76 & 3.75 & 0.328 & 0.386 \\
\hline 62 & 10 & 8.05 & 0.000 & 0.000 & 3.75 & 3.67 & 0.365 & 0.418 \\
\hline
\end{tabular}

${ }^{\text {a }}$ Phosphate concentration based on $\mathrm{P}$ analysis result from inductively coupled plasma-atomic emission spectroscopy (ICP-AES) analysis.

${ }^{b 2}$ Fluoride not measured; assumed equal to one-half of phosphate concentration if $\mathrm{NaF}$ added to sample.

${ }^{\mathrm{c}}$ Nitrate concentration not measured; calculated from input weights of $\mathrm{NaNO}_{3}$ and $\mathrm{H}_{2} \mathrm{O}$.

${ }^{\mathrm{d}}$ Aluminum concentration at equilibrium, as predicted from Equation 3-2.

Equation 3-2 is similar to, but more empirical than, a model used in a 2009 study ("The kinetics of gibbsite dissolution in $\mathrm{NaOH}$ " [Pereira et al 2009]) of gibbsite dissolution rates at 60 to 100 ${ }^{\circ} \mathrm{C}$. Equation 3-3 is the model that those researchers found provided the best fit to their data. Their lower-case $k$ is described as a kinetic rate constant and is equivalent to parameter $b$ in Equation 3-2. Their upper-case $K$ is described as an equilibrium constant $\left(K=\mathrm{C}_{\mathrm{Al}} / \mathrm{C}_{\mathrm{OH}}\right)$, and is equivalent to parameter $a$ in Equation 3-2.

$$
d C_{A l} / d t=k\left(1-C_{A l} / C_{g i b b}^{o}\right)^{2 / 3} C_{O H}\left(1-C_{A l} / K C_{O H}\right)
$$

\subsubsection{Evaluation of Experimental Error for $22{ }^{\circ} \mathrm{C}$ Samples}

Experimental error derived from analytical uncertainty (ICP-AES and free hydroxide analyses) is expected to be small. Of the 100 ambient-temperature samples submitted for analysis, 8 ICP-AES samples and $7 \mathrm{OH}$ samples were run in duplicate (one sample per batch). The average relative percent difference for these duplicate samples was $1.3 \%$ for $\mathrm{Al}, 1.4 \%$ for $\mathrm{Na}$, $1.2 \%$ for $\mathrm{P}$, and $0.9 \%$ for $\mathrm{OH}$.

Errors derived from the weights of reagents added to the sample bottles are expected to be very small. Reagents were weighed on a balance accurate to $\pm 0.01 \mathrm{~g}$, and weights ranged from $0.42 \mathrm{~g}$ 
$(\mathrm{NaF})$ to $80.0 \mathrm{~g}\left(\mathrm{H}_{2} \mathrm{O}\right)$. The gross and tare weights of the sample bottles were used to calculate the total mass added to each bottle, which was compared to the sum of the reagents added to the bottle. The difference between the computed sum and measured sum was never greater than $0.05 \mathrm{~g}$ and was generally less than $0.03 \mathrm{~g}$.

Errors derived from temperature excursions are expected to be small. The temperature of the solution in the sample bottle was recorded each time a sample was taken. These temperatures ranged from 20.8 to $22.9{ }^{\circ} \mathrm{C}$ and were typically at $22.0 \pm 0.5^{\circ} \mathrm{C}$.

Errors derived from sample preparation are likely to be more significant than the errors described above. Some evaporation of water is inevitable when sample bottles are opened and during the filtration process.

Errors derived from conversion of molarity (or $\mu \mathrm{g} / \mathrm{mL}$ ) to molality are also expected to be significant. This conversion depends on the calculated mass of $\mathrm{H}_{2} \mathrm{O}$ in each sample bottle, which depends, in turn, on the measured density (small error) and an estimate of the amount of $\mathrm{H}_{2} \mathrm{O}$ in the solid phase in each bottle as $\mathrm{Na}_{3} \mathrm{PO}_{4} \bullet 12 \mathrm{H}_{2} \mathrm{O}$ or $\mathrm{Na}_{7} \mathrm{~F}\left(\mathrm{PO}_{4}\right)_{2} \bullet 19 \mathrm{H}_{2} \mathrm{O}$ (larger error).

The overall impact of the combined effects of these errors can be evaluated by comparing the results for duplicate test runs. Figure 2 shows the $\mathrm{Al}$ molality vs. time plots (data points and curve fits) for the 8 sets of duplicate runs. In all 8 sets of duplicate runs, the individual data points at 2 weeks and 4 weeks and the projected data at 10 weeks (blue solid line vs. red dotted line), are approximately within $\pm 10 \%$ of each other and in most cases are much better than that. Note that the same can be said about the agreement between the duplicate values in Table 10 for the equilibrium concentration of $\mathrm{Al}$ in runs 5/55 through 12/62. 
Figure 2. Reproducibility of Ambient Temperature Runs.

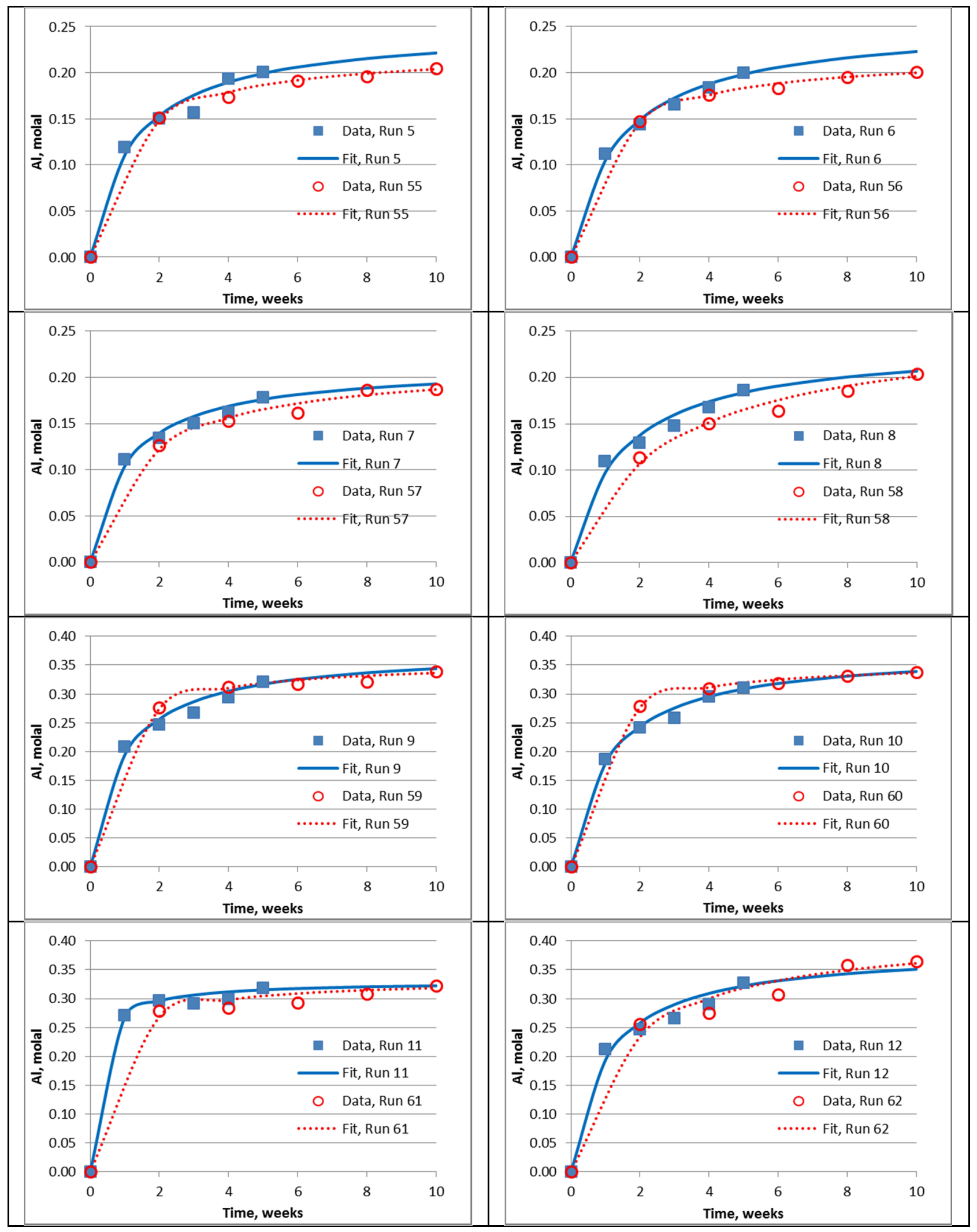




\subsubsection{Effect of Hydroxide Concentration}

Clearly, and as expected, hydroxide concentration had the largest impact of all the parameters (at constant temperature) on the equilibrium Al concentration. In terms of rate of approach to equilibrium, however, there is little indication that hydroxide concentration had much impact. All of the samples at ambient temperature took more-or-less the same amount of time to reach equilibrium, regardless of the hydroxide concentration. This matches the finding of a 2009 study (Pereira et al 2009), which found that hydroxide concentration over the range of 5 to $9 \mathrm{wt} \%$ $\mathrm{NaOH}$ had no significant effect on the rate of gibbsite dissolution over the temperature range of 60 to $100{ }^{\circ} \mathrm{C}$. It also matches the finding of a 2000 study ("The Dissolution and Interactions of Gibbsite Particles in Alkaline Media" [Addai-Mensah et al 2000]), which found that hydroxide concentration over the range of 1 to $8 \mathrm{M} \mathrm{NaOH}$ had no significant effect on the rate of gibbsite dissolution over the temperature range of 25 to $65{ }^{\circ} \mathrm{C}$. See Figure 3 for the dissolution rate data for the current runs 4,58 , and 62 , all of which were at $3.75 \mathrm{~m}$ nitrate and no fluoride or phosphate.

\section{Figure 3. Effect of Hydroxide on Gibbsite Dissolution at Ambient Temperature.}

(Asymptotic Fit Data, Runs at 3.75 m nitrate, no fluoride or phosphate.)

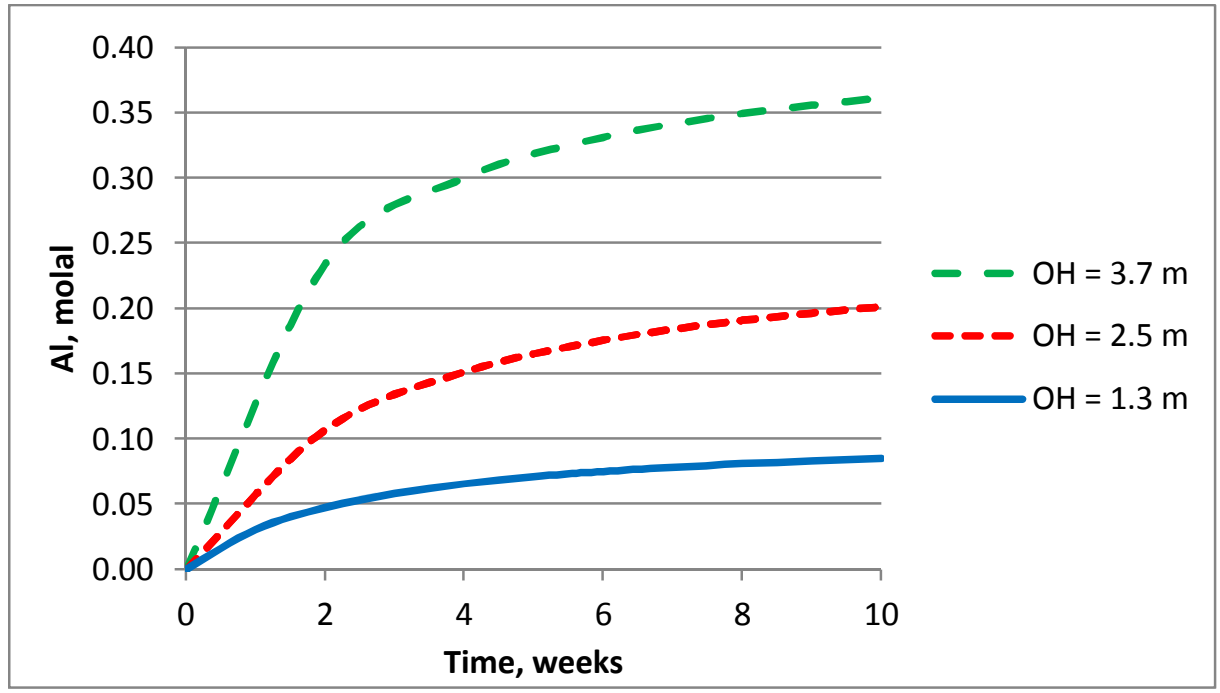

Run 4 at $1.3 \mathrm{~m} \mathrm{OH}$; Run 58 at $2.5 \mathrm{~m} \mathrm{OH}$; Run 62 at $3.7 \mathrm{~m} \mathrm{OH}$ 


\subsubsection{Effect of Nitrate Concentration}

The presence of $3.75 \mathrm{~m}$ sodium nitrate had a subtle but consistent effect on the gibbsite dissolution rate and on the equilibrium Al concentration in solution, as shown in Figure 4 . The dashed lines in this figure represent the asymptotic fits for runs 4,58 , and 62 , at $1.3 \mathrm{~m}, 2.5 \mathrm{~m}$, and $3.7 \mathrm{~m} \mathrm{OH}$, all of which contained $3.75 \mathrm{~m}$ nitrate and no fluoride or phosphate. The corresponding solids lines show runs 3,57 , and 61 at the same $\mathrm{OH}$ concentrations but without any nitrate, phosphate, or fluoride. In all 3 sets of lines, the nitrate had the effect of slowing the approach to equilibrium (i.e., the dashed lines are below the solid lines for the first 2-4 weeks), but increasing the final equilibrium $\mathrm{Al}$ concentration. The magnitude of the effect increases with increasing $\mathrm{OH}$ (and increasing Al). Based on the values in Table 3, the presence of $3.75 \mathrm{~m}$ nitrate results in a $7 \%$ increase in $\mathrm{Al}_{\text {equil }}$ at $1.3 \mathrm{~m} \mathrm{OH}$, a $16 \%$ increase at $2.5 \mathrm{~m} \mathrm{OH}$, and a $21 \%$ increase at $3.7 \mathrm{~m} \mathrm{OH}$.

The effect of nitrate on the dissolution rate is in agreement with an Oak Ridge National Laboratory study ("Experimental Studies of the Solubilities of Aluminum Oxy-Hydroxy Phases to $300 \mathrm{oC}$ " [Palmer et al 2001]), which found that increasing nitrate concentration from 1 to $5 \mathrm{~m}$ caused a reduction in the rate of boehmite dissolution in $1 \mathrm{~m} \mathrm{NaOH}$ at $30{ }^{\circ} \mathrm{C}$. The authors also said that though "the relative rates could not be quantified," increasing ionic strength caused a "marked reduction" in the rate of gibbsite dissolution.

Figure 4. Effect of Nitrate on Gibbsite Dissolution at Ambient Temperature. (Asymptotic Fit Data, no F or $\mathrm{PO}_{4}$; solid lines - $\mathrm{NO}_{3}$ absent; dashed lines - $3.75 \mathrm{~m} \mathrm{NO}_{3}$.) (Same $\mathrm{OH}$ levels as Figure 3.)

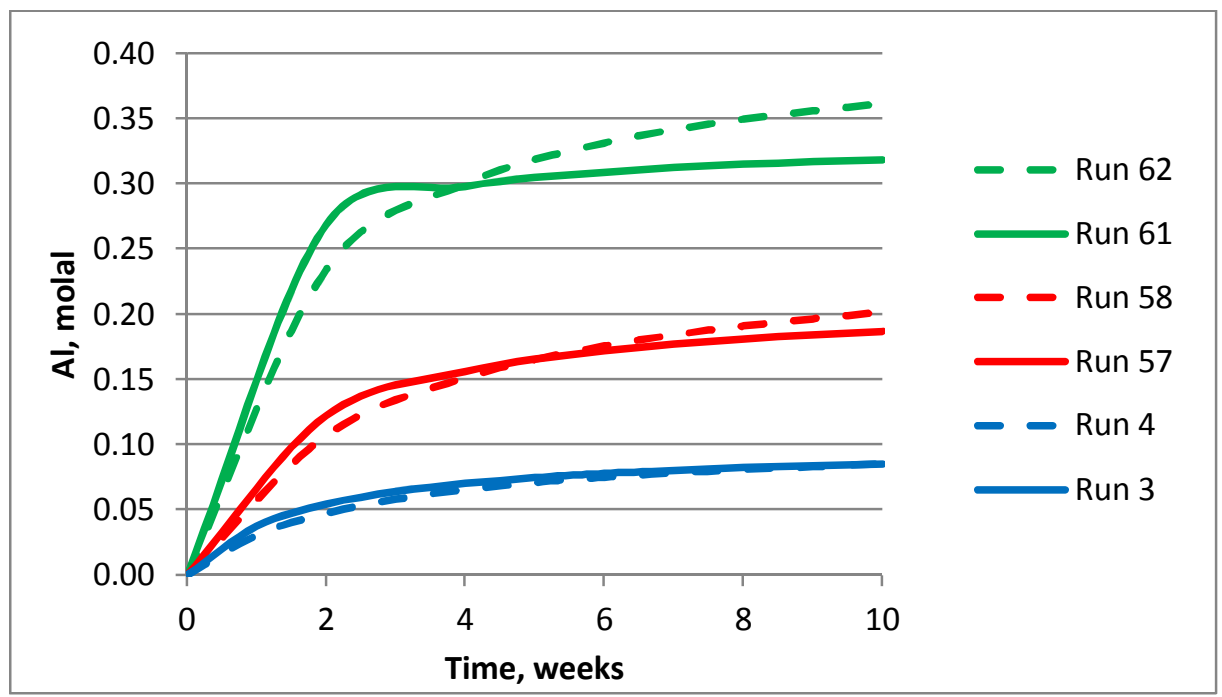




\subsubsection{Effect of Phosphate}

The presence of sodium phosphate had almost no effect on gibbsite dissolution rate, but it did have a subtle but consistent effect on the equilibrium Al concentration in solution, as shown in Figure 5. The dashed lines in this figure represent the asymptotic fits for runs 2, 56, and 60 at saturated sodium phosphate conditions $\left(0.14 \mathrm{~m}, 0.05 \mathrm{~m}\right.$, and $0.03 \mathrm{~m} \mathrm{PO}_{4}$, respectively). The corresponding solids lines show runs 3,57 , and 61 , all of which contained no phosphate, nitrate, or fluoride. In all 3 sets of lines, the phosphate had the effect of increasing the final equilibrium $\mathrm{Al}$ concentration by a small amount. The effect appears to be independent of hydroxide concentration (i.e., the magnitude of the change is roughly the same in all 3 sets of curves). However, considering the change in phosphate solubility with increasing hydroxide (i.e., the change from $0.10 \mathrm{~m} \mathrm{PO}_{4}$ at the lowest $\mathrm{OH}$ level to $0.03 \mathrm{~m} \mathrm{PO}_{4}$ at the highest $\mathrm{OH}$ level), the effect does increase with increasing $\mathrm{OH}$, as did the nitrate effect. In other words, the effect of enhancing the Al solubility is more likely due to an ionic strength (or water activity) effect than it is to the anions themselves.

There was never any indication from microscopic observation of the solids that there was any incorporation of phosphate into any Al-containing solid phase. The only solid phases observed were gibbsite and $\mathrm{Na}_{3} \mathrm{PO}_{4} \bullet 12 \mathrm{H}_{2} \mathrm{O}$.

Figure 5. Effect of Phosphate on Gibbsite Dissolution at Ambient Temperature. (Asymptotic Fit Data, no $\mathrm{F}$ or $\mathrm{NO}_{3}$; solid lines $-\mathrm{PO}_{4}$ absent; dashed lines - saturated in $\mathrm{PO}_{4}$.) (Same OH levels as Figure 3.)

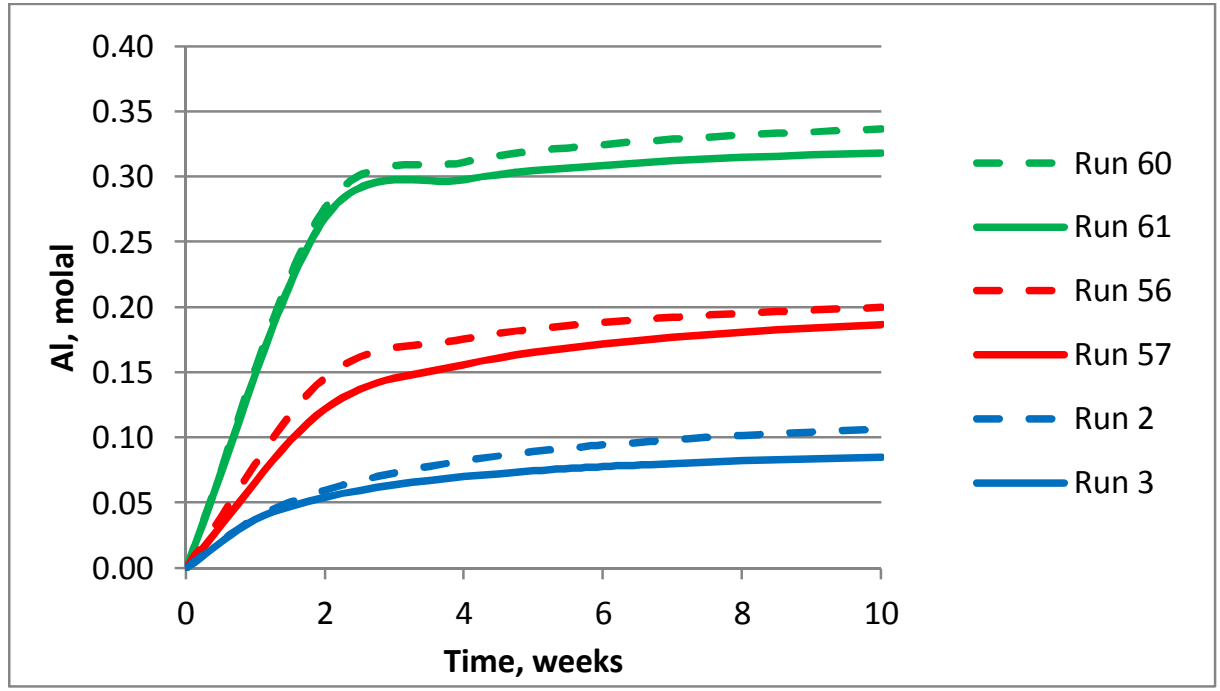




\subsubsection{Fluoride Effect}

Samples that contained fluoride (Runs $1,5 / 55,9 / 59$ ) were saturated in the sodium fluoride phosphate double salt, $\mathrm{Na} 7 \mathrm{~F}\left(\mathrm{PO}_{4}\right)_{2} \bullet 19 \mathrm{H}_{2} \mathrm{O}$. The effect of the fluoride phosphate on gibbsite dissolution rate (none) and gibbsite solubility (slight enhancement) were the same as for phosphate alone, as shown in Figure 6. Figures 5 and 6 appear to be near duplicates of one another. Phosphate concentrations were nearly the same in samples with and without fluoride, as shown in Table 4.

Figure 6. Effect of Fluoride/Phosphate on Gibbsite Dissolution at Ambient Temperature. (Asymptotic Fit Data; solid lines - F and $\mathrm{PO}_{4}$ absent; dashed lines - saturated in $\mathrm{Na} 7 \mathrm{~F}\left(\mathrm{PO}_{4}\right)_{2} \bullet 19 \mathrm{H}_{2} \mathrm{O}$.) (Same $\mathrm{OH}$ levels as Figure 9; nitrate absent.)

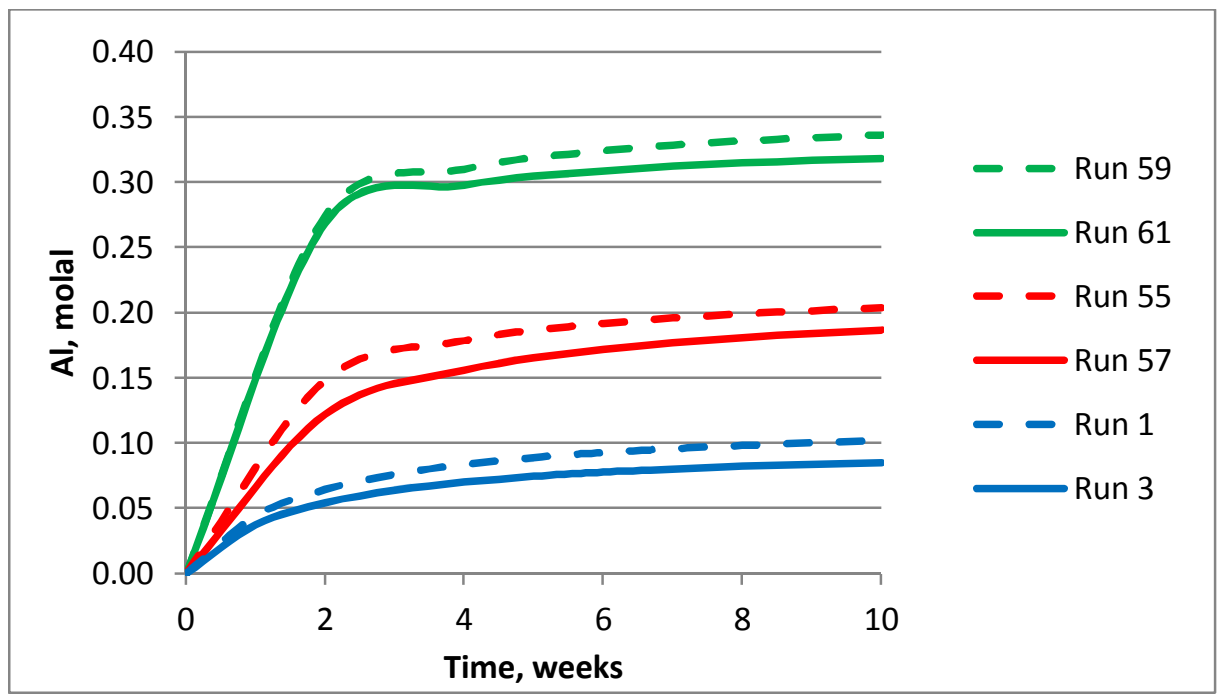

Table 4. Concentration (in molality) of Phosphate in Ambient Temperature Samples.

\begin{tabular}{|c|c|c|}
\hline OH, molal & $\begin{array}{c}\text { F Present } \\
\text { (Runs 1, 5/55, 9/59) }\end{array}$ & $\begin{array}{c}\text { F Absent } \\
\text { (Runs 2, 6/56, 10/60) }\end{array}$ \\
\hline 1.3 & 0.10 & 0.14 \\
\hline 2.5 & 0.05 & 0.05 \\
\hline 3.7 & 0.03 & 0.03 \\
\hline
\end{tabular}

\subsubsection{Comparison to Literature Data}

Equilibrium aluminum concentrations (in molality) from Table 3 are compared to literature data for gibbsite solubility at $25{ }^{\circ} \mathrm{C}$ ("The influence of $\mathrm{Al}(\mathrm{III})$ supersaturation and $\mathrm{NaOH}$ concentration on the rate of crystallization of $\mathrm{Al}(\mathrm{OH}) 3$ precursor particles from sodium aluminate solutions" [ $\mathrm{Li}$ et al 2005]) in Figure 7. The solid line represents the literature data. The diamond-shaped points represent samples with no phosphate, fluoride, or nitrate added (samples ALP2-3, -7, -11, -57, -61). These points generally fall slightly below the literature 
curve, possibly due to the $3{ }^{\circ} \mathrm{C}$ temperature difference $\left(25{ }^{\circ} \mathrm{C}\right.$ for the literature data, $22{ }^{\circ} \mathrm{C}$ for the current samples). The square data points represent samples containing $3.75 \mathrm{~m}$ sodium nitrate (samples ALP2-4, -8, -12, -58, -62). These points generally fall above the literature line, representing the influence of nitrate (or ionic strength or water activity) on the gibbsite solubility. Points representing samples saturated in $\mathrm{Na}_{3} \mathrm{PO}_{4} \bullet 12 \mathrm{H}_{2} \mathrm{O}$ (circles) or $\mathrm{Na} 7 \mathrm{~F}\left(\mathrm{PO}_{4}\right)_{2} \bullet 19 \mathrm{H}_{2} \mathrm{O}$ (triangles) fall virtually on the literature curve, intermediate between the diamonds and squares.

\section{Figure 7. Comparison of Sample Data $\left(22^{\circ} \mathrm{C}\right)$ to Literature Data $\left(25^{\circ} \mathrm{C}\right)$ for Gibbsite} Solubility.

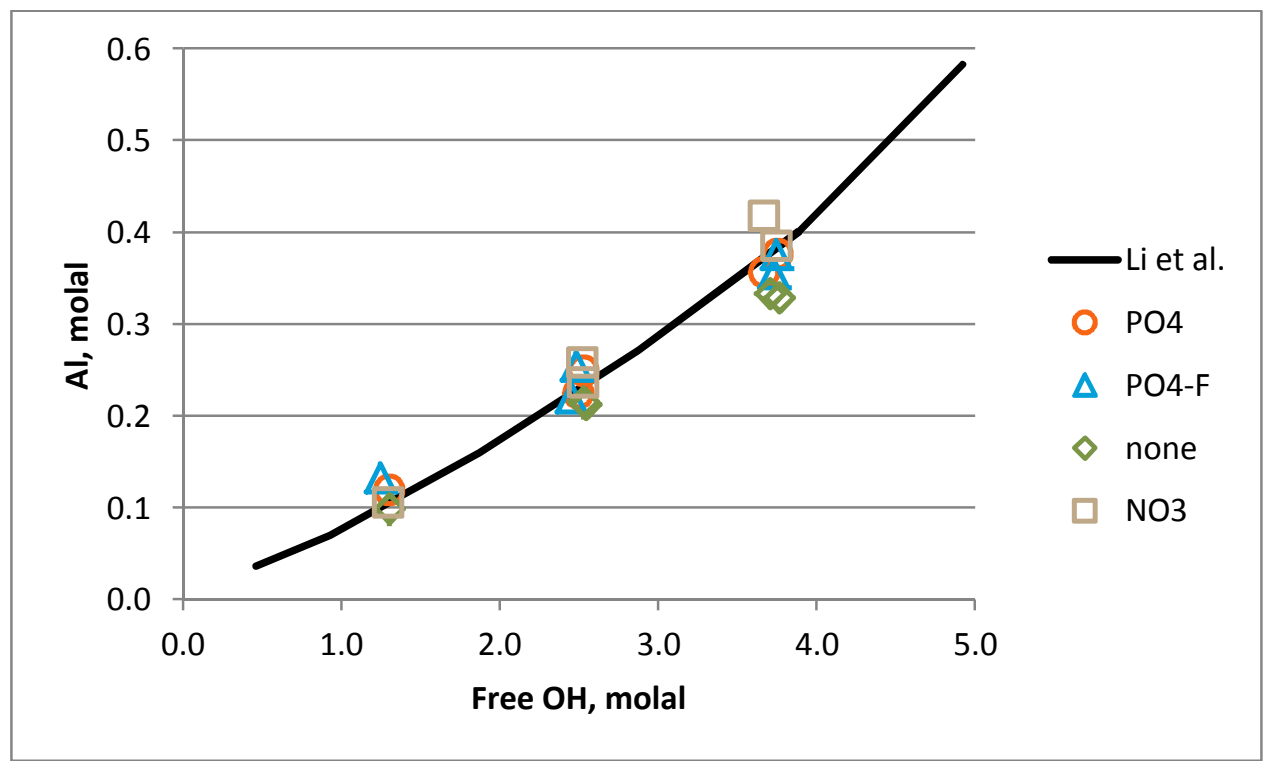

(Li et al. 2005 data as amended by personal communication from Jacob Reynolds) 


\subsection{ELEVATED TEMPERATURE RESULTS}

Runs $21-27$ were conducted at $40{ }^{\circ} \mathrm{C}$ with samples taken at 1-day intervals for 4 days plus a final sample at 7 days. Analytical results are shown in Tables A-7 through A-9 in Appendix A. Results show that none of the samples reached equilibrium (i.e., constant Al concentration).

Runs 28 - 32 were done with sampling at intervals of $1,4,7,10$, and 14 days. Runs $41-47$ (repeat of Runs 21 - 27) were done with sampling at intervals of 1, 5, 7, 9, and 14 days. Analytical results are shown in Tables A-10 through A-12 in Appendix A.

Several of the samples still had not reached equilibrium after 14 days. Plots of $\mathrm{Al}$ molality as a function of time are shown in Appendix B. As with the ambient-temperature runs, the $40{ }^{\circ} \mathrm{C}$ plots were fitted with the asymptotic function in Equation 3-2, and the "Solver" function in Microsoft Excel was used to optimize the values of the parameters. (For Run 47, the Solver returned a "division by zero" error, so the fit was made manually in that case.) The predicted values for $\mathrm{Al}_{\text {equil }}$ are collected in Table 5 along with the measured (or calculated) concentrations of the other solution components at the final sampling point $(\mathrm{t}=7$ days or $\mathrm{t}=14$ days $)$ for all of the $40{ }^{\circ} \mathrm{C}$ runs.

Table 5. Concentrations (in molality) at Final Sampling Point for $40{ }^{\circ} \mathrm{C}$ Samples.

\begin{tabular}{|c|c|c|c|c|c|c|c|c|}
\hline Run & $\begin{array}{l}\text { Time, } \\
\text { Days }\end{array}$ & $\begin{array}{c}\mathrm{Na}^{+} \\
\text {molal }\end{array}$ & $\begin{array}{l}\mathrm{PO}_{4}{ }^{3-} \\
\text { molal }^{\mathrm{a}}\end{array}$ & $\begin{array}{c}\mathbf{F}^{-} \\
\text {molal }^{b}\end{array}$ & $\begin{array}{c}\mathrm{NO}_{3}{ }^{-} \\
\text {molal }^{\mathrm{c}}\end{array}$ & $\begin{array}{c}\mathrm{OH}^{-} \\
\text {molal }\end{array}$ & $\begin{array}{c}\mathbf{A l}_{\text {measured }} \\
\text { molal }\end{array}$ & $\begin{array}{l}\mathrm{Al}_{\text {equil }} \\
\text { molal }^{\mathrm{d}}\end{array}$ \\
\hline 21 & 7 & 2.23 & 0.19 & 0.09 & 0.00 & 1.34 & 0.21 & 0.23 \\
\hline 41 & 14 & 2.23 & 0.20 & 0.10 & 0.00 & 1.33 & 0.18 & 0.21 \\
\hline 22 & 7 & 2.79 & 0.40 & 0.00 & 0.00 & 1.28 & 0.20 & 0.21 \\
\hline 42 & 14 & 2.72 & 0.44 & 0.00 & 0.00 & 1.20 & 0.16 & 0.18 \\
\hline 23 & 7 & 1.69 & 0.00 & 0.00 & 0.00 & 1.40 & 0.19 & 0.21 \\
\hline 43 & 14 & 1.53 & 0.00 & 0.00 & 0.00 & 1.34 & 0.16 & 0.16 \\
\hline 24 & 7 & 5.98 & 0.00 & 0.00 & 3.75 & 1.34 & 0.17 & 0.20 \\
\hline 44 & 14 & 5.33 & 0.00 & 0.00 & 3.75 & 1.33 & 0.18 & 0.20 \\
\hline 25 & 7 & 3.72 & 0.10 & 0.05 & 0.00 & 2.62 & 0.38 & 0.45 \\
\hline 45 & 14 & 3.44 & 0.11 & 0.05 & 0.00 & 2.65 & 0.37 & 0.42 \\
\hline 26 & 7 & 3.86 & 0.20 & 0.00 & 0.00 & 2.53 & 0.37 & 0.43 \\
\hline 46 & 14 & 3.46 & 0.21 & 0.00 & 0.00 & 2.49 & 0.36 & 0.38 \\
\hline 27 & 7 & 3.45 & 0.00 & 0.00 & 0.00 & 2.63 & 0.38 & 0.40 \\
\hline 47 & 14 & 3.09 & 0.00 & 0.00 & 0.00 & 2.52 & 0.45 & 0.46 \\
\hline 28 & 14 & 6.52 & 0.00 & 0.00 & 3.75 & 2.41 & 0.41 & 0.44 \\
\hline 29 & 14 & 4.78 & 0.08 & 0.04 & 0.00 & 3.77 & 0.65 & 0.66 \\
\hline 30 & 14 & 4.81 & 0.14 & 0.00 & 0.00 & 3.66 & 0.65 & 0.65 \\
\hline 31 & 14 & 4.52 & 0.00 & 0.00 & 0.00 & 3.81 & 0.64 & 0.66 \\
\hline 32 & 14 & 8.16 & 0.00 & 0.00 & 3.75 & 3.60 & 0.76 & 0.79 \\
\hline
\end{tabular}

${ }^{a}$ Phosphate concentration based on P analysis result from inductively coupled plasma-atomic emission spectroscopy (ICP-AES) analysis.

${ }^{\mathrm{b}}$ Fluoride not measured; assumed equal to one-half of phosphate concentration if $\mathrm{NaF}$ added to sample.

${ }^{\mathrm{c}}$ Nitrate concentration not measured; calculated from input weights of $\mathrm{NaNO}_{3}$ and $\mathrm{H}_{2} \mathrm{O}$.

${ }^{\mathrm{d}}$ Aluminum concentration at equilibrium, as predicted from Equation 3-2. 


\subsubsection{Evaluation of Experimental Error}

Experimental error derived from analytical uncertainty (ICP-AES and free hydroxide analyses) for the $40{ }^{\circ} \mathrm{C}$ samples, like the ambient-temperature samples, is expected to be small. Of the 95 samples submitted for analysis, $6 \mathrm{ICP}$-AES samples and $11 \mathrm{OH}$ samples were run in duplicate (one sample per batch). The average relative percent difference for these duplicate samples was $2.8 \%$ for $\mathrm{Al}, 2.2 \%$ for $\mathrm{Na}, 3.7 \%$ for $\mathrm{P}$, and $1.3 \%$ for $\mathrm{OH}$.

Errors derived from the weights of reagents added to the sample bottles are expected to be very small. The reagents were weighed on a balance accurate to $\pm 0.01 \mathrm{~g}$, and weights ranged from $0.84 \mathrm{~g}(\mathrm{NaF})$ to $80.0 \mathrm{~g}\left(\mathrm{H}_{2} \mathrm{O}\right)$. The gross and tare weights of the sample bottles were used to calculate the total mass added to each bottle, which was compared to the sum of the reagents added to the bottle. The difference between the computed sum and measured sum was never greater than $0.11 \mathrm{~g}$ and was generally less than $0.06 \mathrm{~g}$.

Errors derived from temperature excursions are expected to be small. The temperature of the solution in the sample bottle was recorded each time a sample was taken. These temperatures ranged from 38.4 to $41.2{ }^{\circ} \mathrm{C}$, and were typically at $40.0 \pm 1.0{ }^{\circ} \mathrm{C}$.

Errors derived from sample preparation are likely to be more significant than the errors described above. Some evaporation of water is inevitable when sample bottles are opened and during the filtration process, and sample dilutions were necessary to prevent precipitation of salts before the samples were analyzed.

Errors derived from conversion of molarity (or $\mu \mathrm{g} / \mathrm{mL}$ ) to molality are also expected to be significant. This conversion depends on the calculated mass of $\mathrm{H}_{2} \mathrm{O}$ in each sample bottle, which depends, in turn, on the measured density (small error) and an estimate of the amount of $\mathrm{H}_{2} \mathrm{O}$ in the solid phase in each bottle as $\mathrm{Na}_{3} \mathrm{PO}_{4} \bullet 12 \mathrm{H}_{2} \mathrm{O}$ or $\mathrm{Na}_{7} \mathrm{~F}\left(\mathrm{PO}_{4}\right)_{2} \bullet 19 \mathrm{H}_{2} \mathrm{O}$ (larger error).

One potential source of error for the $40{ }^{\circ} \mathrm{C}$ samples that was not present for the ambienttemperature samples was the degree of mixing. Ambient-temperature samples were continually rotated using a Labquake mixer, which provided nearly perfect mixing of solid and liquid phases during the test. The $40{ }^{\circ} \mathrm{C}$ samples were kept in a shaking water bath which provided generally poorer contact of the settled solids with the liquid phase. This is likely the dominant source or discrepancy between duplicate sample runs for the $40{ }^{\circ} \mathrm{C}$ samples.

The overall impact of the combined effects of these errors can be evaluated by comparing the results for duplicate test runs. Figure 8 shows the Al molality vs. time plots (data points and curve fits) for the 7 sets of duplicate runs. (Note that, based on the Day 5 sample and the Day 1 results for similar samples, the reported Al concentration for Run 47 Day 1 appears to be too high by a factor of two. Re-examination of the analytical data failed to uncover any inconsistencies.) 
Figure 8. Reproducibility of $40^{\circ} \mathrm{C}$ Runs.

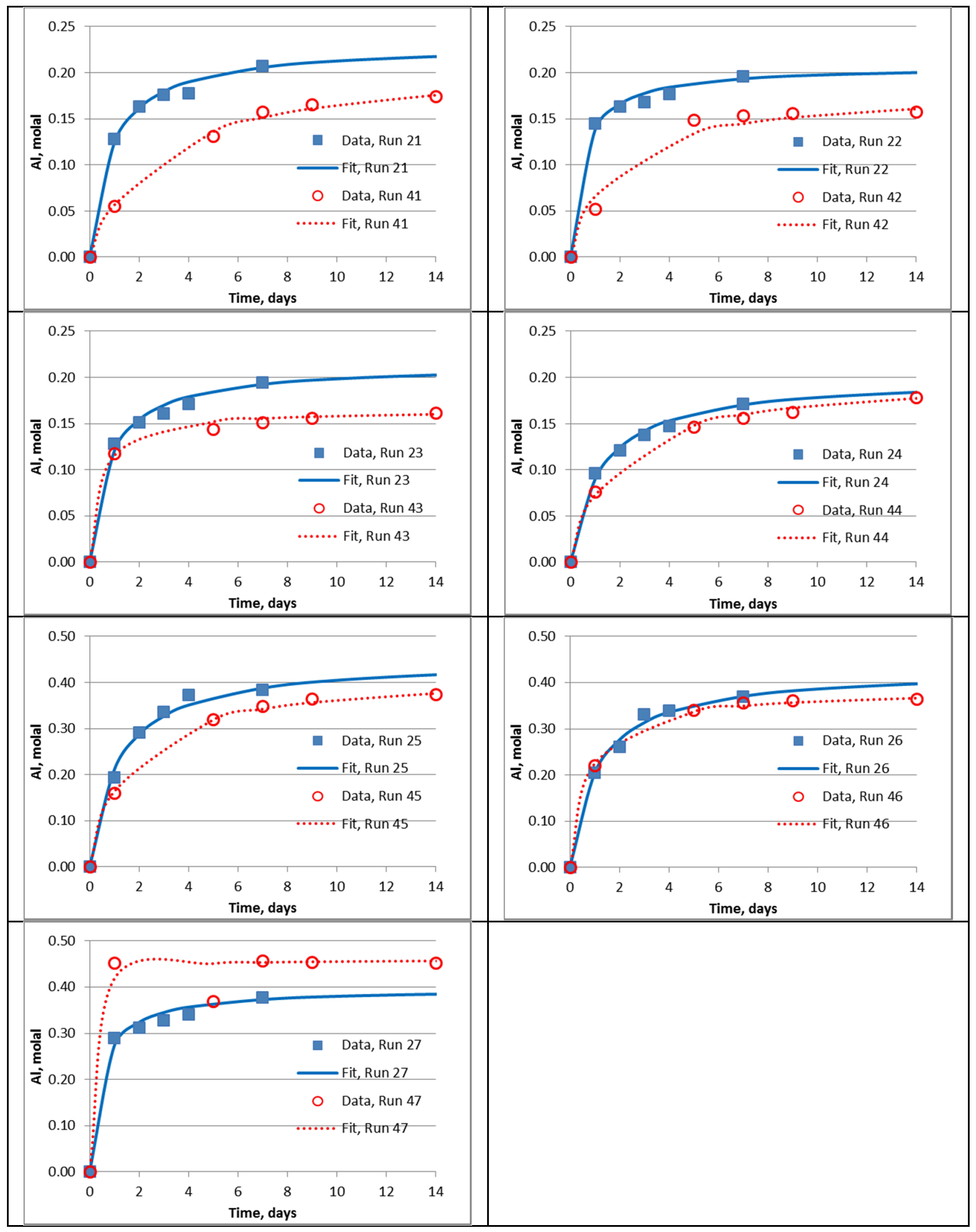




\subsubsection{Effect of Hydroxide Concentration}

Clearly, as with the ambient-temperature runs, hydroxide concentration had the largest impact of all the parameters on the equilibrium $\mathrm{Al}$ concentration. In terms of rate of approach to equilibrium, however, there is little indication that hydroxide concentration had much impact. All of the samples at $40{ }^{\circ} \mathrm{C}$ took more-or-less the same amount of time to reach equilibrium, regardless of the hydroxide concentration. See Figure 9 for the dissolution rate data for runs 23/43, 27/47, and 31, all of which were at zero fluoride, phosphate, and nitrate.

Figure 9. Effect of Hydroxide on Gibbsite Dissolution at $40^{\circ} \mathrm{C}$.

(Asymptotic Fit Data, Runs at zero fluoride, phosphate, and nitrate.)

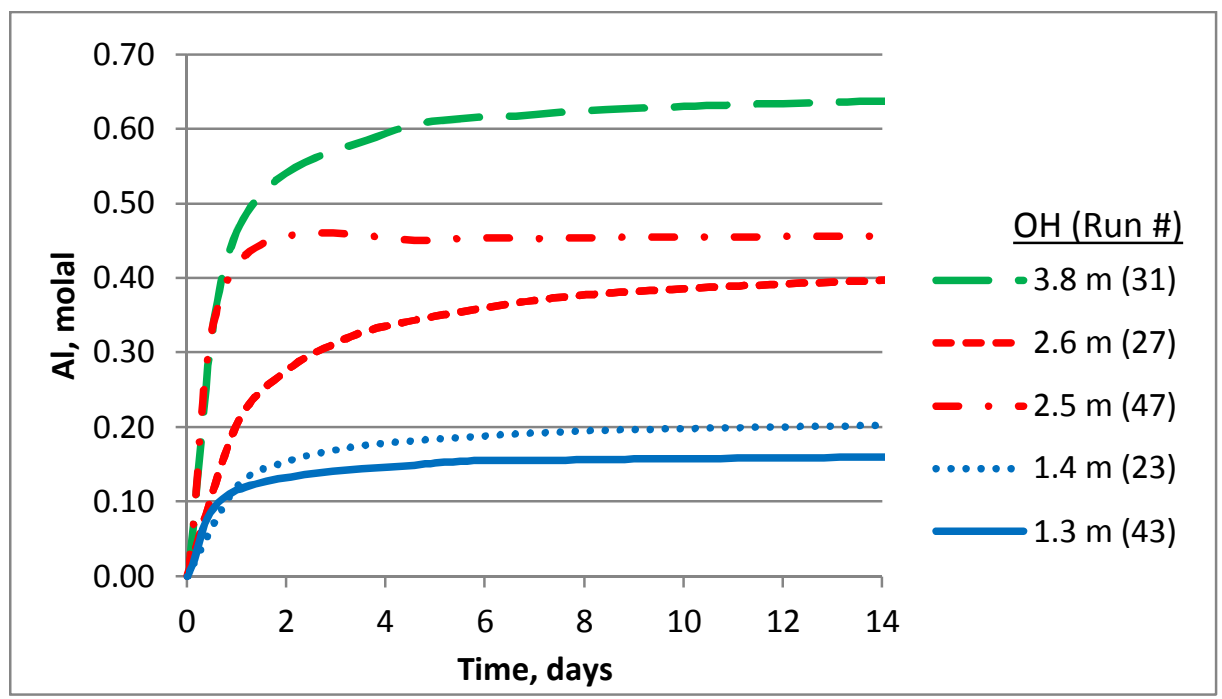




\subsubsection{Effect of Nitrate Concentration}

The presence of $3.75 \mathrm{~m}$ sodium nitrate had a subtle effect on gibbsite dissolution rate at $40{ }^{\circ} \mathrm{C}$ and on the equilibrium Al concentration in solution, as shown in Figure 10. The dashed lines in this figure represent the asymptotic fits for runs $24 / 44,28$, and 32, at $1.3 \mathrm{~m}, 2.5 \mathrm{~m}$, and $3.7 \mathrm{~m}$ $\mathrm{OH}$, all of which contained $3.75 \mathrm{~m}$ nitrate. The corresponding solid lines show runs 23/43, 27, and 31 at the same $\mathrm{OH}$ concentrations but without any nitrate, phosphate, or fluoride. At $1.3 \mathrm{~m}$ and $2.5 \mathrm{~m} \mathrm{OH}$, the nitrate had the effect of slowing the approach to equilibrium (i.e., the dashed lines are below the solid lines for the first 1-5 days), but the final equilibrium Al concentration was the same, within the analytical uncertainty in these runs. At $3.7 \mathrm{~m} \mathrm{OH}$, the nitrate appeared to have no effect on the rate of dissolution, but like the ambient-temperature samples, it did increase the gibbsite solubility by about $20 \%$.

Figure 10. Effect of Nitrate on Gibbsite Dissolution at $40{ }^{\circ} \mathrm{C}$.

(Asymptotic Fit Data, no F or $\mathrm{PO}_{4}$; solid lines - $\mathrm{NO}_{3}$ absent; dashed lines - $3.75 \mathrm{~m} \mathrm{NO}$.)

(Same OH levels as Figure 9.)

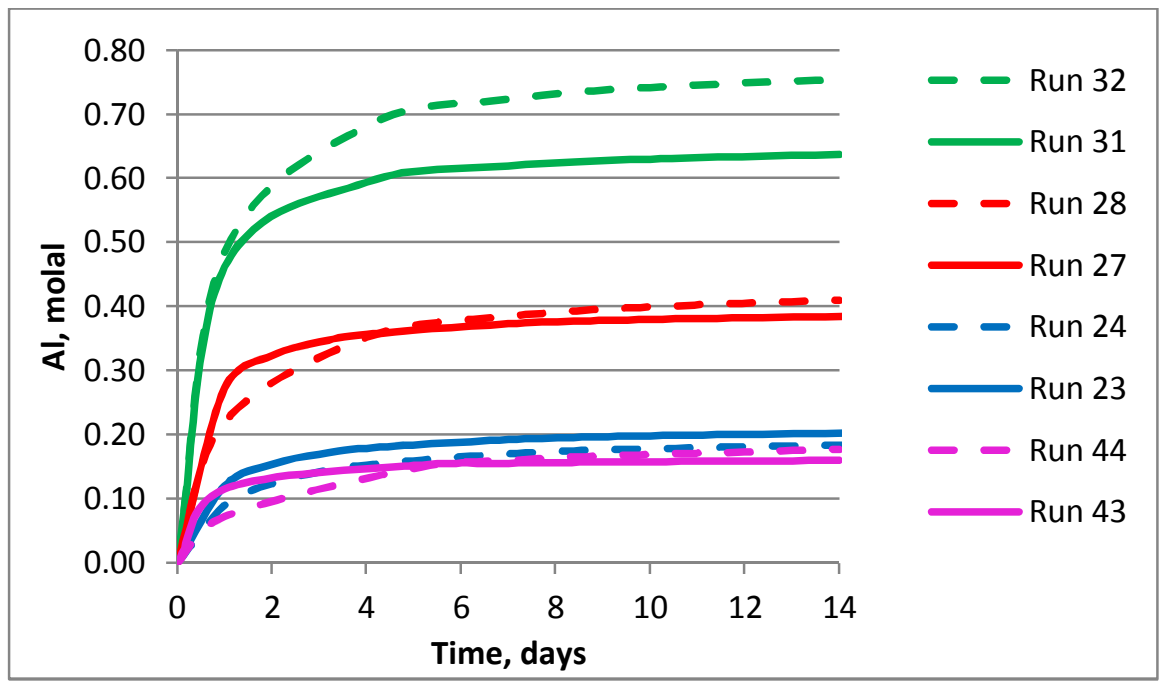




\subsubsection{Effect of Phosphate and Fluoride}

The presence of sodium phosphate (or the sodium fluoride phosphate double salt) had no discernable effect on gibbsite dissolution rate or equilibrium $\mathrm{Al}$ concentration at $40{ }^{\circ} \mathrm{C}$, as shown in Figures 11 and 12. The dashed lines in Figure 11 represent the asymptotic fits for runs 22, 26, and 30 at saturated sodium phosphate conditions $\left(0.42 \mathrm{~m}, 0.20 \mathrm{~m}\right.$, and $0.14 \mathrm{~m} \mathrm{PO}_{4}$, respectively). The corresponding solid lines show runs 23,27 , and 31, all of which contained no phosphate, nitrate, or fluoride. In all 3 sets of lines, the difference between the dashed lines and solid lines is either inconsistent or within experimental error.

The dashed lines in Figure 12 represent the asymptotic fits for runs 21, 25, and 29 at saturated sodium fluoride phosphate conditions $\left(0.19 \mathrm{~m}, 0.10 \mathrm{~m}\right.$, and $0.08 \mathrm{~m} \mathrm{PO}_{4}$, respectively). The corresponding solid lines are the same as they were in Figure 9 (no nitrate, fluoride, or phosphate). Although the equilibrium Al concentration is higher for the dashed line in all 3 cases (i.e., at all $3 \mathrm{OH}$ levels), the difference does not exceed experimental error.

\section{Figure 11. Effect of Phosphate on Gibbsite Dissolution at $40{ }^{\circ} \mathrm{C}$.}

(Asymptotic Fit Data, no $\mathrm{F}$ or $\mathrm{NO}_{3}$; solid lines - $\mathrm{PO}_{4}$ absent; dashed lines - saturated in $\mathrm{PO}_{4}$.)

(Same OH levels as Figure 9.)

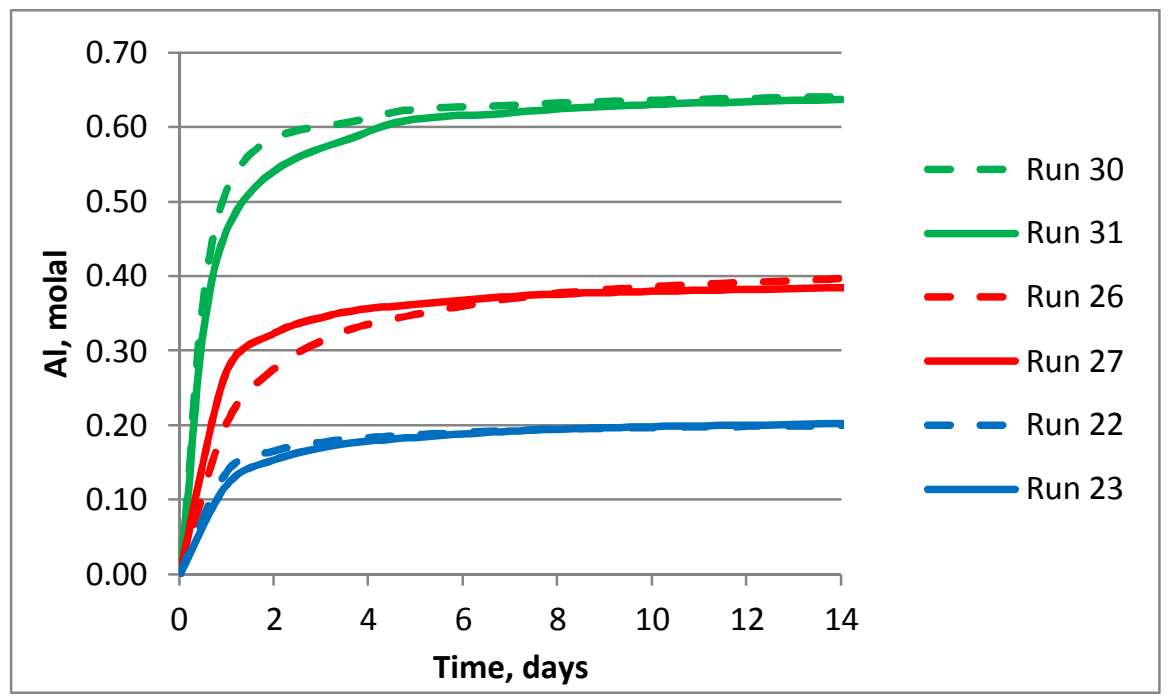


Figure 12. Effect of Fluoride/Phosphate on Gibbsite Dissolution at $40{ }^{\circ} \mathrm{C}$.

(Asymptotic Fit Data; solid lines - F and $\mathrm{PO}_{4}$ absent; dashed lines - saturated in $\mathrm{Na} 7 \mathrm{~F}\left(\mathrm{PO}_{4}\right)_{2} \bullet 19 \mathrm{H}_{2} \mathrm{O}$.) (Same OH levels as Figure 9; nitrate absent.)

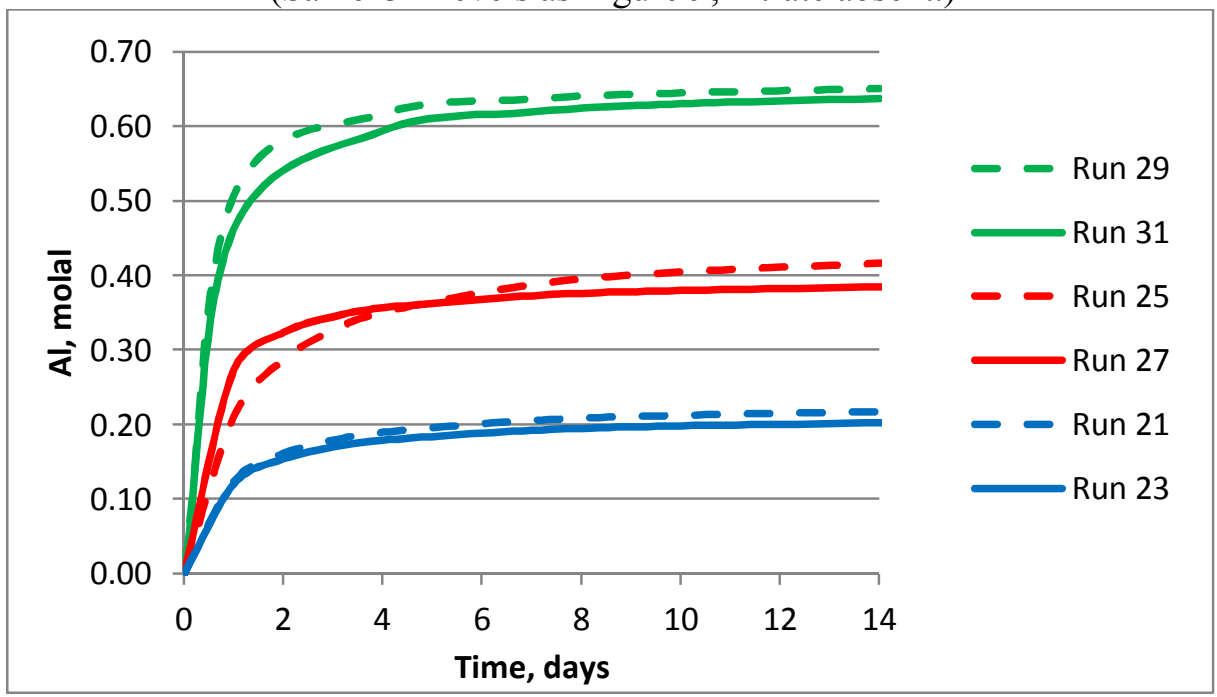

At ambient temperature, the presence of fluoride had little effect on the overall solubility of phosphate (see Table 4). At $40{ }^{\circ} \mathrm{C}$, however, the fluoride had a strongly inhibiting effect on phosphate solubility, as shown in Table 6.

Table 6. Concentrations (in molality) of Phosphate in $40^{\circ} \mathrm{C}$ Samples.

\begin{tabular}{|c|c|c|}
\hline OH, molal & $\begin{array}{c}\text { F Present } \\
\text { (Runs 21/41, 25/45, 29) }\end{array}$ & $\begin{array}{c}\text { F Absent } \\
\text { (Runs 22/42, 26/46, 30) }\end{array}$ \\
\hline 1.3 & 0.19 & 0.42 \\
\hline 2.5 & 0.10 & 0.20 \\
\hline 3.7 & 0.08 & 0.14 \\
\hline
\end{tabular}

\subsubsection{Comparison to $40{ }^{\circ} \mathrm{C}$ Literature Data}

Equilibrium aluminum concentrations (in molality) from Table 5 are compared to literature data for gibbsite solubility at $40{ }^{\circ} \mathrm{C}$ ("Solubility and Density of Hydrated Aluminas in $\mathrm{NaOH}$ Solutions" [Russell et al. 1955]) in Figure 13. The solid line represents the literature data. The diamond-shaped points represent samples with no phosphate, fluoride, or nitrate added (samples ALP2-23, -27, -31). These points generally fall very close to the literature curve. The square data points represent samples containing 3.75 m sodium nitrate (samples ALP2-24, -28, -32). These points generally fall above the literature line, representing the influence of nitrate (or ionic strength or water activity) on the gibbsite solubility. Points representing samples saturated in $\mathrm{Na}_{3} \mathrm{PO}_{4} \bullet 12 \mathrm{H}_{2} \mathrm{O}$ (circles) or $\mathrm{Na}_{7} \mathrm{~F}\left(\mathrm{PO}_{4}\right)_{2} \bullet 19 \mathrm{H}_{2} \mathrm{O}$ (triangles) are generally intermediate between the diamonds and squares. 
Figure 13. Comparison of Sample Data $\left(40{ }^{\circ} \mathrm{C}\right)$ to Literature Data $\left(40^{\circ} \mathrm{C}\right)$ for Gibbsite Solubility.

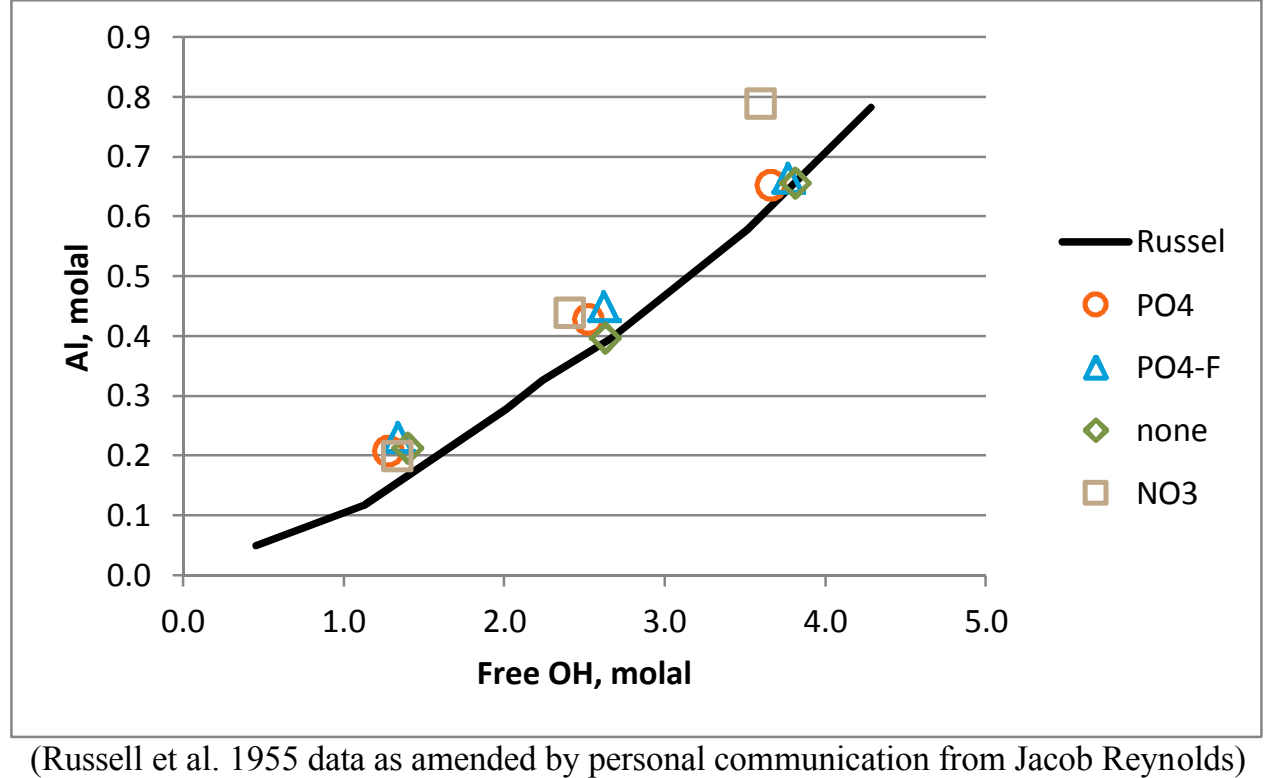




\section{COMPARISON TO COMPUTER MODEL PREDICTIONS}

Experimental results for Runs 1 - 12 (ambient temperature) and $21-32\left(40{ }^{\circ} \mathrm{C}\right)$ were provided to System Planning and Modeling for the purpose of comparing experimental aluminum solubility data with numbers predicted by the Environmental Simulation Program (ESP) computer model. The data provided included the measured concentrations (in molarity) of hydroxide and phosphate, and the solution density in $\mathrm{g} / \mathrm{mL}$. Fluoride concentration was assumed to be exactly half of the measured phosphate concentration (for samples that included fluoride).

Nitrate concentration was assumed to be the calculated value based on the mass of $\mathrm{NaNO}_{3}$ added to the samples.

The experimental data were used as input to the Analyzer Studio (AS) function of the ESP software. The steps involved in calculating the aluminum solubility were:

1. Enter the sample compositions (in molarity) into AS 9.0.

2. Perform an equilibrium calculation.

3. Create an output stream composition.

4. Let AS calculate the Al precipitation point for this new stream.

5. Compare the resulting free $\mathrm{OH}$ concentration of the new stream with the input stream; increase the free $\mathrm{OH}$ in the new stream to match (or exceed) the input stream.

6. Iterate the $\mathrm{Al}$ precipitation point calculation until the resulting free $\mathrm{OH}$ concentration matches the original input stream.

7. Record the final output stream composition.

The AS software provided equilibrium concentrations (in molarity) of hydroxide, phosphate, fluoride, nitrate, and aluminate, plus solution density in $\mathrm{g} / \mathrm{mL}$ and weight percent water. The density and $\% \mathrm{H}_{2} \mathrm{O}$ values were used to convert the molarity data to molality units. Results are shown in Table 7 beside the experimental $\mathrm{Al}_{\text {equil }}$ values from Table 3 and Table 5.

The agreement between the ESP-predicted results and the experimental results is generally good, but there are some consistent discrepancies.

ESP tended to predict that phosphate and/or phosphate/fluoride would lower the Al solubility by a very small amount. Experimentally, the opposite is true. The ESP results imply that there is some Al-PO4 interaction, which would cause the Al solubility to decrease, rather than increase due to the ionic strength effect. However, such an interaction does not appear to be present.

ESP correctly predicts that adding $\mathrm{NaNO}_{3}$ would increase the Al solubility. Experimentally, however, the magnitude of the increase is not as great as ESP predicts, especially at $40{ }^{\circ} \mathrm{C}$.

Finally, the effect of hydroxide concentration is not as great experimentally as the ESP results would predict. Thus, the Al/OH curve is "flatter" for the experimental data than it is for the ESP results, as shown in Figure 14, for both the $22{ }^{\circ} \mathrm{C}$ and $40{ }^{\circ} \mathrm{C}$ data. 
Table 7. Comparison of Experimental Data ${ }^{1}\left(\mathrm{Al}_{\text {equil }}\right)$ with Environmental Simulation Program-Predicted Data ( $\left.\mathrm{Al}_{\mathrm{ESP}}\right)$.

(Concentrations in Molality)

\begin{tabular}{|c|c|c|c|c|c|}
\hline Run & $\mathbf{T ~} \mathbf{(}^{\mathbf{0}} \mathbf{C}$ & $\mathbf{O H}$ & $\mathbf{A d d e d ~ S a l t}$ & $\mathbf{A l}_{\text {equil }}$ & $\mathbf{A l}_{\text {ESP }}$ \\
\hline 1 & 22 & 1.30 & $\mathrm{PO}_{4}-\mathrm{F}$ & 0.119 & 0.079 \\
\hline 2 & 22 & 1.24 & $\mathrm{PO}_{4}$ & 0.133 & 0.074 \\
\hline 3 & 22 & 1.30 & $\mathrm{None}$ & 0.100 & 0.083 \\
\hline 4 & 22 & 1.30 & $\mathrm{NO}_{3}$ & 0.106 & 0.100 \\
\hline 5 & 22 & 2.53 & $\mathrm{PO}_{4}-\mathrm{F}$ & 0.249 & 0.190 \\
\hline 6 & 22 & 2.48 & $\mathrm{PO}_{4}$ & 0.255 & 0.184 \\
\hline 7 & 22 & 2.54 & $\mathrm{None}$ & 0.213 & 0.192 \\
\hline 8 & 22 & 2.53 & $\mathrm{NO}_{3}$ & 0.237 & 0.224 \\
\hline 9 & 22 & 3.76 & $\mathrm{PO}_{4}-\mathrm{F}$ & 0.376 & 0.383 \\
\hline 10 & 22 & 3.75 & $\mathrm{PO}_{4}$ & 0.376 & 0.383 \\
\hline 11 & 22 & 3.76 & $\mathrm{None}$ & 0.330 & 0.385 \\
\hline 12 & 22 & 3.75 & $\mathrm{NO}_{3}$ & 0.386 & 0.421 \\
\hline 21 & 40 & 1.34 & $\mathrm{PO}_{4}-\mathrm{F}$ & 0.231 & 0.146 \\
\hline 22 & 40 & 1.28 & $\mathrm{PO}_{4}$ & 0.207 & 0.142 \\
\hline 23 & 40 & 1.40 & $\mathrm{None}$ & 0.214 & 0.163 \\
\hline 24 & 40 & 1.34 & $\mathrm{NO}_{3}$ & 0.200 & 0.243 \\
\hline 25 & 40 & 2.62 & $\mathrm{PO}_{4}-\mathrm{F}$ & 0.451 & 0.372 \\
\hline 26 & 40 & 2.53 & $\mathrm{PO}_{4}$ & 0.429 & 0.359 \\
\hline 27 & 40 & 2.63 & $\mathrm{None}$ & 0.397 & 0.382 \\
\hline 28 & 40 & 2.41 & $\mathrm{NO}_{3}$ & 0.440 & 0.549 \\
\hline 29 & 40 & 3.77 & $\mathrm{PO}_{4}-\mathrm{F}$ & 0.665 & 0.746 \\
\hline 30 & 40 & 3.66 & $\mathrm{PO}_{4}$ & 0.653 & 0.723 \\
\hline 31 & 40 & 3.81 & $\mathrm{None}_{3}$ & 0.657 & 0.768 \\
\hline 32 & 40 & 3.60 & $\mathrm{NO}_{3}$ & 0.789 & 1.180 \\
\hline
\end{tabular}

${ }^{1} \mathrm{OH}$ molality is taken from the last-measured data point for each run. $\mathrm{Al}_{\text {equil }}$ molality is taken from a fit to the experimental data using Equation 4-2, as described earlier. 


\section{Figure 14. Comparison of Experimental Data with Environmental Simulation Program Predictions.}

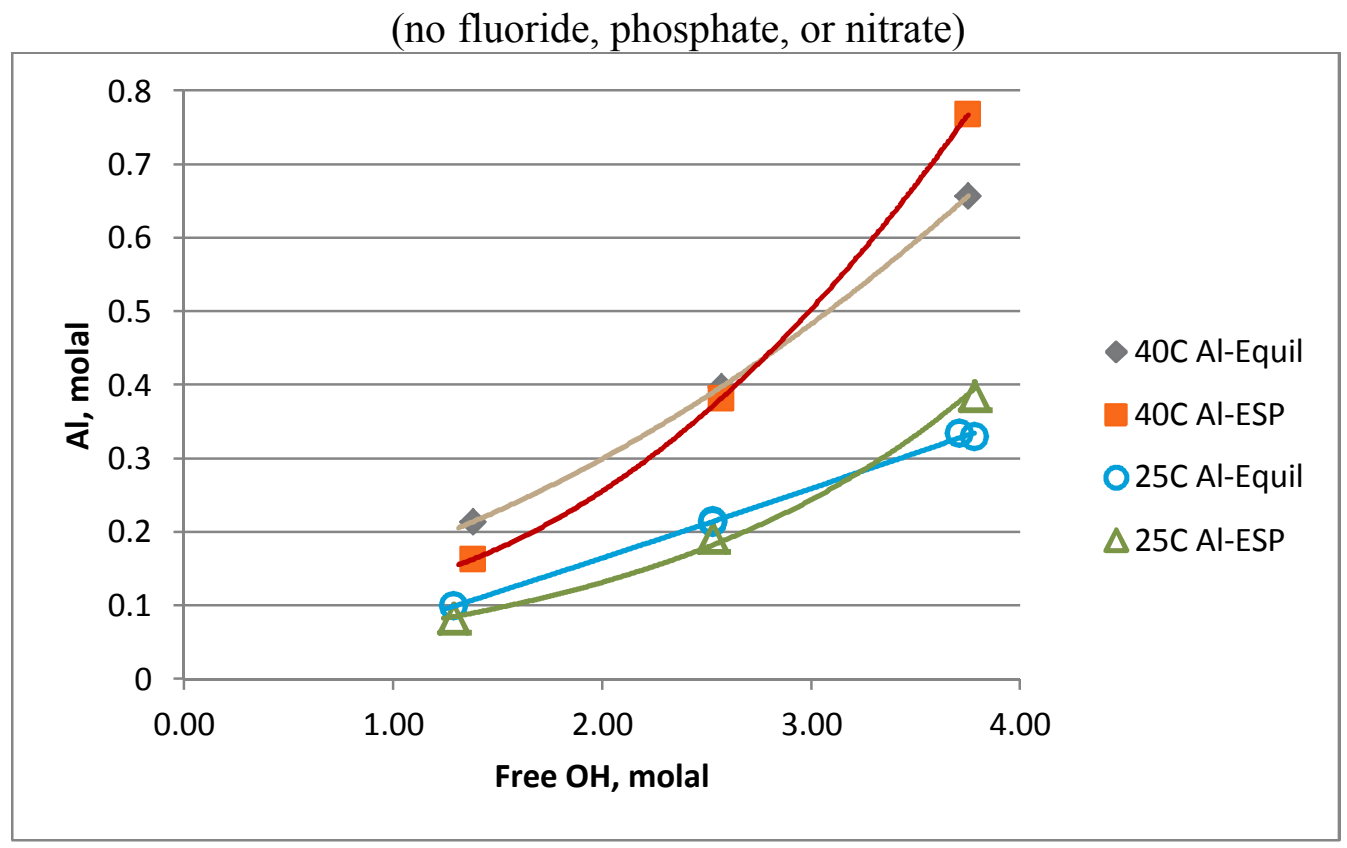

\section{ACKNOWLEDGEMENTS}

Nearly all of the laboratory work for this study (sample preparation, mixing, filtration, density measurement, etc.) was skillfully performed by Margaret LaMothe. Sample analyses (ICP-AES, $\mathrm{OH}$ titrations) were performed by Advanced Technologies and Laboratories International, Inc., personnel. Computer modeling work (ESP) was performed by Kayla Pierson and Q. D. Ho of WRPS System Planning and Modeling.

\section{REFERENCES}

Addai-Mensah, J. D., J. Dawe, and J. Ralston (2000), "The Dissolution and Interactions of Gibbsite Particles in Alkaline Media," in Proceedings of the XXI International Mineral Processing Congress, Rome, Italy.

Li, H, J. Addai-Mensah, J. C. Thomas, and A. R. Gerson, 2005, “The influence of Al(III) supersaturation and $\mathrm{NaOH}$ concentration on the rate of crystallization of $\mathrm{Al}(\mathrm{OH}) 3$ precursor particles from sodium aluminate solutions," J. Colloid and Interface Science, Vol. 286, pp. 511-519. 
Palmer, D. A., P. Benezeth, D. J. Wesolowski, and S. Hilic, "Experimental Studies of the Solubilities of Aluminum Oxy-Hydroxy Phases to 300 oC," 2001, (http://web.ornl.gov/ webworks/cppr/y2001/pres/120198.pdf).

Pereira, J. A. M., M. Schwaab, E. Dell'Oro, J. C. Pinto, J. L. F. Monteiro, and C. A. Henriques, 2009, "The kinetics of gibbsite dissolution in NaOH," Hydrometallurgy, Vol. 96, pp. 613.

Russell, A. S., J. D. Edwards, and C. S. Taylor, "Solubility and Density of Hydrated Aluminas in NaOH Solutions,” Journal of Metals, Vol. 7, 1955, pp. 1123-1128. 


\section{Appendix A}

Analytical Results for Gibbsite Dissolution Samples. 
LAB-RPT-13-00011 Rev 0 Appendix A

Table A-1. Analytical Results for Ambient-Temperature Samples ALP2-1 through ALP2-12.

\begin{tabular}{|c|c|c|c|c|c|c|c|c|c|c|c|c|}
\hline Week & 1 & 2 & 3 & 4 & 5 & 6 & 7 & 8 & 9 & 10 & 11 & 12 \\
\hline & \multicolumn{12}{|c|}{ Density, g/mL } \\
\hline 1 & 1.076 & 1.072 & (1.255) & 1.216 & 1.118 & 1.114 & 1.102 & 1.251 & 1.155 & 1.158 & 1.154 & 1.287 \\
\hline 2 & 1.075 & 1.078 & 1.055 & 1.214 & 1.117 & 1.115 & 1.111 & 1.251 & 1.160 & 1.162 & 1.159 & 1.294 \\
\hline 3 & 1.076 & 1.077 & 1.056 & 1.219 & 1.116 & 1.114 & 1.105 & 1.250 & 1.160 & 1.160 & 1.158 & 1.295 \\
\hline 4 & 1.078 & 1.076 & 1.055 & 1.213 & 1.115 & 1.116 & 1.105 & 1.251 & 1.162 & 1.160 & 1.158 & 1.294 \\
\hline \multirow[t]{2}{*}{5} & 1.077 & 1.078 & 1.057 & 1.218 & 1.117 & 1.115 & 1.107 & 1.254 & 1.165 & 1.161 & 1.158 & 1.295 \\
\hline & \multicolumn{12}{|c|}{$\mathrm{Al}, \boldsymbol{\mu g} / \mathrm{mL}$} \\
\hline 1 & 1270 & 1120 & 1080 & 801 & 3160 & 2970 & 2950 & 2560 & 5460 & 4900 & 7160 & 4920 \\
\hline 2 & 1680 & 1580 & 1450 & 1110 & 3980 & 3810 & 3570 & 3030 & 6470 & 6350 & 7820 & 5730 \\
\hline 3 & 1960 & 1870 & 1580 & 1300 & 4150 & 4380 & 4000 & 3460 & 7020 & 6780 & 7670 & 6180 \\
\hline 4 & 2220 & 2200 & 1860 & 1530 & 5120 & 4870 & 4310 & 3930 & 7700 & 7750 & 7870 & 6730 \\
\hline \multirow[t]{2}{*}{5} & 2400 & 2410 & 2020 & 1700 & 5310 & 5280 & 4730 & 4360 & 8410 & 8140 & 8400 & 7600 \\
\hline & \multicolumn{12}{|c|}{$\mathrm{Na}, \mu \mathrm{g} / \mathrm{mL}$} \\
\hline 1 & 42100 & 41400 & 32900 & 111000 & 68400 & 68200 & 64400 & 138000 & 96900 & 94200 & 94100 & 161000 \\
\hline 2 & 41500 & 41400 & 33100 & 108000 & 70400 & 67500 & 64700 & 134000 & 97500 & 98100 & 97700 & 158000 \\
\hline 3 & 42100 & 40600 & 31800 & 104000 & 65500 & 66900 & 64900 & 133000 & 95900 & 94100 & 93400 & 155000 \\
\hline 4 & 41900 & 41500 & 33100 & 107000 & 72100 & 66600 & 64000 & 135000 & 95900 & 97700 & 91600 & 151000 \\
\hline \multirow[t]{2}{*}{5} & 42700 & 43300 & 33500 & 109000 & 71000 & 69000 & 66500 & 139000 & 99300 & 96600 & 95500 & 160000 \\
\hline & \multicolumn{12}{|c|}{$P, \mu g / m L$} \\
\hline 1 & 3180 & 4170 & 0 & 0 & 1610 & 1660 & 0 & 0 & 925 & 947 & 0 & 0 \\
\hline 2 & 3270 & 4200 & 0 & 0 & 1730 & 1800 & 0 & 0 & 1010 & 1010 & 0 & 0 \\
\hline 3 & 3120 & 4180 & 0 & 0 & 1620 & 1670 & 0 & 0 & 918 & 926 & 0 & 0 \\
\hline 4 & 3140 & 4120 & 0 & 0 & 1660 & 1620 & 0 & 0 & 939 & 976 & 0 & 0 \\
\hline \multirow[t]{2}{*}{5} & 3300 & 4460 & 0 & 0 & 1760 & 1810 & 0 & 0 & 1010 & 1000 & 0 & 0 \\
\hline & \multicolumn{12}{|c|}{$\mathrm{OH}, \mu \mathrm{g} / \mathrm{mL}$} \\
\hline 1 & 22900 & 21900 & 22700 & 19900 & 43700 & 43300 & 43200 & 38300 & 63300 & 63700 & 62600 & 56300 \\
\hline 2 & 22700 & 21600 & 22400 & 19900 & 43000 & 42400 & 43200 & 37900 & 63300 & 63200 & 63100 & 56000 \\
\hline 3 & 22300 & 21300 & 22400 & 19700 & 43000 & 42300 & 43200 & 37900 & 62800 & 62800 & 62600 & 55600 \\
\hline 4 & 22200 & 21000 & 22000 & 19600 & 42200 & 41600 & 42500 & 37600 & 62300 & 59000 & 60700 & 55100 \\
\hline 5 & 22000 & 21000 & 22000 & 19400 & 42100 & 41300 & 42500 & 37300 & 61900 & 61800 & 62400 & 54700 \\
\hline
\end{tabular}


LAB-RPT-13-00011 Rev 0 Appendix A

Table A-2. Samples ALP2-1 through ALP2-12, Concentrations in Molarity.

\begin{tabular}{|c|c|c|c|c|c|c|c|c|c|c|c|c|}
\hline Week & 1 & 2 & 3 & 4 & 5 & 6 & 7 & 8 & 9 & 10 & 11 & 12 \\
\hline & \multicolumn{12}{|c|}{ Al, $\mathbf{M}$} \\
\hline 1 & 0.047 & 0.041 & 0.040 & 0.030 & 0.117 & 0.110 & 0.109 & 0.095 & 0.202 & 0.181 & 0.265 & 0.182 \\
\hline 2 & 0.062 & 0.059 & 0.054 & 0.041 & 0.147 & 0.141 & 0.132 & 0.112 & 0.240 & 0.235 & 0.290 & 0.212 \\
\hline 3 & 0.073 & 0.069 & 0.059 & 0.048 & 0.154 & 0.162 & 0.148 & 0.128 & 0.260 & 0.251 & 0.284 & 0.229 \\
\hline 4 & 0.082 & 0.081 & 0.069 & 0.057 & 0.190 & 0.180 & 0.160 & 0.146 & 0.285 & 0.287 & 0.291 & 0.249 \\
\hline \multirow[t]{2}{*}{5} & 0.089 & 0.089 & 0.075 & 0.063 & 0.197 & 0.196 & 0.175 & 0.161 & 0.311 & 0.301 & 0.311 & 0.281 \\
\hline & \multicolumn{12}{|c|}{$\mathrm{Na}, \mathrm{M}$} \\
\hline 1 & 1.830 & 1.800 & 1.430 & 4.826 & 2.974 & 2.965 & 2.800 & 6.000 & 4.213 & 4.096 & 4.091 & 7.000 \\
\hline 2 & 1.804 & 1.800 & 1.439 & 4.696 & 3.061 & 2.935 & 2.813 & 5.826 & 4.239 & 4.265 & 4.248 & 6.870 \\
\hline 3 & 1.830 & 1.765 & 1.383 & 4.522 & 2.848 & 2.909 & 2.822 & 5.783 & 4.170 & 4.091 & 4.061 & 6.739 \\
\hline 4 & 1.822 & 1.804 & 1.439 & 4.652 & 3.135 & 2.896 & 2.783 & 5.870 & 4.170 & 4.248 & 3.983 & 6.565 \\
\hline \multirow[t]{2}{*}{5} & 1.857 & 1.883 & 1.457 & 4.739 & 3.087 & 3.000 & 2.891 & 6.043 & 4.317 & 4.200 & 4.152 & 6.957 \\
\hline & \multicolumn{12}{|c|}{$\mathbf{P}, \mathbf{M}$} \\
\hline 1 & 0.103 & 0.135 & 0.000 & 0.000 & 0.052 & 0.054 & 0.000 & 0.000 & 0.030 & 0.031 & 0.000 & 0.000 \\
\hline 2 & 0.105 & 0.135 & 0.000 & 0.000 & 0.056 & 0.058 & 0.000 & 0.000 & 0.033 & 0.033 & 0.000 & 0.000 \\
\hline 3 & 0.101 & 0.135 & 0.000 & 0.000 & 0.052 & 0.054 & 0.000 & 0.000 & 0.030 & 0.030 & 0.000 & 0.000 \\
\hline 4 & 0.101 & 0.133 & 0.000 & 0.000 & 0.054 & 0.052 & 0.000 & 0.000 & 0.030 & 0.031 & 0.000 & 0.000 \\
\hline \multirow[t]{2}{*}{5} & 0.106 & 0.144 & 0.000 & 0.000 & 0.057 & 0.058 & 0.000 & 0.000 & 0.033 & 0.032 & 0.000 & 0.000 \\
\hline & \multicolumn{12}{|c|}{ OH, M } \\
\hline 1 & 1.347 & 1.288 & 1.335 & 1.171 & 2.571 & 2.547 & 2.541 & 2.253 & 3.724 & 3.747 & 3.682 & 3.312 \\
\hline 2 & 1.335 & 1.271 & 1.318 & 1.171 & 2.529 & 2.494 & 2.541 & 2.229 & 3.724 & 3.718 & 3.712 & 3.294 \\
\hline 3 & 1.312 & 1.253 & 1.318 & 1.159 & 2.529 & 2.488 & 2.541 & 2.229 & 3.694 & 3.694 & 3.682 & 3.271 \\
\hline 4 & 1.306 & 1.235 & 1.294 & 1.153 & 2.482 & 2.447 & 2.500 & 2.212 & 3.665 & 3.471 & 3.571 & 3.241 \\
\hline 5 & 1.294 & 1.235 & 1.294 & 1.141 & 2.476 & 2.429 & 2.500 & 2.194 & 3.641 & 3.635 & 3.671 & 3.218 \\
\hline
\end{tabular}


Table A-3. Samples ALP2-1 through ALP2-12, Concentrations in Molality.

\begin{tabular}{|c|c|c|c|c|c|c|c|c|c|c|c|c|}
\hline & 1 & 2 & 3 & 4 & 5 & 6 & 7 & 8 & 9 & 10 & 11 & 12 \\
\hline & \multicolumn{12}{|c|}{ Conversion Factors } \\
\hline $\mathrm{g}^{1}$ & 89.15 & 88.97 & 85.08 & 110.59 & 93.07 & 92.92 & 90.00 & 115.54 & 97.02 & 96.93 & 94.98 & 120.54 \\
\hline $\mathrm{mL}^{2}$ & 82.82 & 82.68 & 80.58 & 90.93 & 83.34 & 83.36 & 81.39 & 92.33 & 83.61 & 83.55 & 82.06 & 93.22 \\
\hline $\mathrm{g}^{3}$ & 82.17 & 82.19 & 80.02 & 80.01 & 81.63 & 81.63 & 80.01 & 80.03 & 81.08 & 81.08 & 80.01 & 80.00 \\
\hline $\mathrm{kg} / \mathrm{L}^{4}$ & 0.992 & 0.994 & 0.993 & 0.880 & 0.979 & 0.979 & 0.983 & 0.867 & 0.970 & 0.971 & 0.975 & 0.858 \\
\hline Week & \multicolumn{12}{|c|}{$\mathbf{A l}, \mathbf{m}$} \\
\hline 1 & 0.047 & 0.042 & 0.040 & 0.034 & 0.119 & 0.112 & 0.111 & 0.109 & 0.209 & 0.187 & 0.272 & 0.212 \\
\hline 2 & 0.063 & 0.059 & 0.054 & 0.047 & 0.150 & 0.144 & 0.134 & 0.129 & 0.247 & 0.242 & 0.297 & 0.247 \\
\hline 3 & 0.073 & 0.070 & 0.059 & 0.055 & 0.157 & 0.166 & 0.151 & 0.148 & 0.268 & 0.259 & 0.291 & 0.267 \\
\hline 4 & 0.083 & 0.082 & 0.069 & 0.064 & 0.194 & 0.184 & 0.162 & 0.168 & 0.294 & 0.296 & 0.299 & 0.290 \\
\hline \multirow[t]{2}{*}{5} & 0.090 & 0.090 & 0.075 & 0.072 & 0.201 & 0.200 & 0.178 & 0.186 & 0.321 & 0.311 & 0.319 & 0.328 \\
\hline & \multicolumn{12}{|c|}{ Na, $\mathbf{m}$} \\
\hline 1 & 1.845 & 1.811 & 1.440 & 5.485 & 3.036 & 3.028 & 2.848 & 6.922 & 4.344 & 4.220 & 4.196 & 8.157 \\
\hline 2 & 1.819 & 1.811 & 1.449 & 5.337 & 3.125 & 2.997 & 2.861 & 6.721 & 4.371 & 4.395 & 4.357 & 8.005 \\
\hline 3 & 1.845 & 1.776 & 1.392 & 5.139 & 2.908 & 2.971 & 2.870 & 6.671 & 4.299 & 4.216 & 4.165 & 7.853 \\
\hline 4 & 1.836 & 1.815 & 1.449 & 5.287 & 3.201 & 2.957 & 2.830 & 6.772 & 4.299 & 4.377 & 4.085 & 7.650 \\
\hline \multirow[t]{2}{*}{5} & 1.871 & 1.894 & 1.467 & 5.386 & 3.152 & 3.064 & 2.941 & 6.972 & 4.452 & 4.328 & 4.259 & 8.106 \\
\hline & \multicolumn{12}{|c|}{$\mathbf{P}, \mathbf{m}$} \\
\hline 1 & 0.103 & 0.135 & 0.000 & 0.000 & 0.053 & 0.055 & 0.000 & 0.000 & 0.031 & 0.031 & 0.000 & 0.000 \\
\hline 2 & 0.106 & 0.136 & 0.000 & 0.000 & 0.057 & 0.059 & 0.000 & 0.000 & 0.034 & 0.034 & 0.000 & 0.000 \\
\hline 3 & 0.101 & 0.136 & 0.000 & 0.000 & 0.053 & 0.055 & 0.000 & 0.000 & 0.031 & 0.031 & 0.000 & 0.000 \\
\hline 4 & 0.102 & 0.134 & 0.000 & 0.000 & 0.055 & 0.053 & 0.000 & 0.000 & 0.031 & 0.032 & 0.000 & 0.000 \\
\hline \multirow[t]{2}{*}{5} & 0.107 & 0.145 & 0.000 & 0.000 & 0.058 & 0.060 & 0.000 & 0.000 & 0.034 & 0.033 & 0.000 & 0.000 \\
\hline & \multicolumn{12}{|c|}{ OH, m } \\
\hline 1 & 1.358 & 1.296 & 1.345 & 1.330 & 2.624 & 2.601 & 2.585 & 2.599 & 3.839 & 3.861 & 3.777 & 3.859 \\
\hline 2 & 1.346 & 1.278 & 1.327 & 1.330 & 2.582 & 2.547 & 2.585 & 2.572 & 3.839 & 3.831 & 3.807 & 3.838 \\
\hline 3 & 1.322 & 1.260 & 1.327 & 1.317 & 2.582 & 2.541 & 2.585 & 2.572 & 3.809 & 3.806 & 3.777 & 3.811 \\
\hline 4 & 1.316 & 1.243 & 1.303 & 1.310 & 2.534 & 2.499 & 2.543 & 2.552 & 3.779 & 3.576 & 3.662 & 3.777 \\
\hline 5 & 1.304 & 1.243 & 1.303 & 1.297 & 2.528 & 2.481 & 2.543 & 2.531 & 3.755 & 3.746 & 3.765 & 3.749 \\
\hline
\end{tabular}

${ }^{\mathrm{T}}$ Mass (g) of liquid phase based on mass of reagents added, assuming $25 \%$ dissolution of gibbsite, sodium phosphate, and sodium fluoride.

${ }^{2}$ Volume $(\mathrm{mL})$ of liquid phase, based on calculated total mass and measured density.

${ }^{3}$ Mass ( $\mathrm{g}$ ) of $\mathrm{H}_{2} \mathrm{O}$, assuming $25 \%$ dissolution of sodium phosphate reagent.

${ }^{4}$ Mass $(\mathrm{kg})$ of $\mathrm{H}_{2} \mathrm{O}$ per $\mathrm{L}$ of liquid phase. 
Table A-4. Analytical Results for Ambient-Temperature Samples ALP2-55 through ALP2-62.

\begin{tabular}{|c|c|c|c|c|c|c|c|c|}
\hline Week & 55 & 56 & 57 & 58 & 59 & 60 & 61 & 62 \\
\hline & \multicolumn{8}{|c|}{ Density, g/mL } \\
\hline 2 & 1.117 & 1.112 & 1.110 & 1.255 & 1.158 & 1.160 & 1.159 & 1.292 \\
\hline 4 & 1.117 & 1.112 & 1.110 & 1.255 & 1.158 & 1.160 & 1.159 & 1.292 \\
\hline 6 & 1.119 & 1.116 & 1.108 & 1.256 & 1.162 & 1.162 & 1.162 & 1.293 \\
\hline 8 & 1.117 & 1.115 & 1.113 & 1.255 & 1.163 & 1.163 & 1.160 & 1.294 \\
\hline \multirow[t]{2}{*}{10} & 1.119 & 1.115 & 1.113 & 1.256 & 1.162 & 1.163 & 1.158 & 1.296 \\
\hline & \multicolumn{8}{|c|}{ Al, $\mu \mathrm{g} / \mathrm{mL}$} \\
\hline 2 & 4010 & 3890 & 3380 & 2670 & 7240 & 7320 & 7370 & 5940 \\
\hline 4 & 4600 & 4660 & 4070 & 3540 & 8170 & 8130 & 7480 & 6390 \\
\hline 6 & 5060 & 4850 & 4320 & 3850 & 8300 & 8350 & 7720 & 7110 \\
\hline 8 & 5190 & 5150 & 4980 & 4360 & 8400 & 8690 & 8130 & 8310 \\
\hline \multirow[t]{2}{*}{10} & 5420 & 5300 & 5000 & 4780 & 8880 & 8860 & 8520 & 8460 \\
\hline & \multicolumn{8}{|c|}{$\mathrm{Na}, \mu \mathrm{g} / \mathrm{mL}$} \\
\hline 2 & 65500 & 64400 & 59400 & 124000 & 91600 & 92800 & 93400 & 151000 \\
\hline 4 & 65100 & 63900 & 60900 & 128000 & 95500 & 93600 & 91400 & 141000 \\
\hline 6 & 67400 & 62700 & 60700 & 123000 & 93200 & 93000 & 90300 & 146000 \\
\hline 8 & 66600 & 64800 & 65500 & 128000 & 90800 & 92500 & 89800 & 157000 \\
\hline \multirow[t]{2}{*}{10} & 68600 & 66300 & 64400 & 135000 & 96600 & 95600 & 94400 & 159000 \\
\hline & \multicolumn{8}{|c|}{$\mathrm{P}, \mu \mathrm{g} / \mathrm{mL}$} \\
\hline 2 & 1620 & 1690 & 0 & 0 & 927 & 961 & 966 & 0 \\
\hline 4 & 1660 & 1600 & 0 & 0 & 969 & 922 & 0 & 0 \\
\hline 6 & 1500 & 1440 & 0 & 0 & 868 & 837 & 0 & 0 \\
\hline 8 & 1470 & 1520 & 0 & 0 & 878 & 868 & 0 & 0 \\
\hline \multirow[t]{2}{*}{10} & 1520 & 1590 & 0 & 0 & 895 & 900 & 0 & 0 \\
\hline & \multicolumn{8}{|c|}{$\mathrm{OH}, \mu \mathrm{g} / \mathrm{mL}$} \\
\hline 2 & 42500 & 42100 & 43600 & 38700 & 61700 & 61700 & 61700 & 55300 \\
\hline 4 & 42200 & 41500 & 42900 & 37700 & 61400 & 61600 & 62500 & 54600 \\
\hline 6 & 41400 & 40500 & 42800 & 37900 & 61500 & 75200 & 62600 & 52600 \\
\hline 8 & 41800 & 41300 & 42400 & 37500 & 61000 & 60700 & 62100 & 53700 \\
\hline 10 & 41600 & 40800 & 42500 & 37300 & 60500 & 61600 & 61600 & 53600 \\
\hline
\end{tabular}


Table A-5. Samples ALP2-1 through ALP2-12, Concentrations in Molarity.

\begin{tabular}{|c|c|c|c|c|c|c|c|c|}
\hline Week & 55 & 56 & 57 & 58 & 59 & 60 & 61 & 62 \\
\hline & \multicolumn{8}{|c|}{ Al, $\mathbf{M}$} \\
\hline 2 & 0.149 & 0.144 & 0.125 & 0.099 & 0.268 & 0.271 & 0.273 & 0.220 \\
\hline 4 & 0.170 & 0.173 & 0.151 & 0.131 & 0.303 & 0.301 & 0.277 & 0.237 \\
\hline 6 & 0.187 & 0.180 & 0.160 & 0.143 & 0.307 & 0.309 & 0.286 & 0.263 \\
\hline 8 & 0.192 & 0.191 & 0.184 & 0.161 & 0.311 & 0.322 & 0.301 & 0.308 \\
\hline \multirow[t]{2}{*}{10} & 0.201 & 0.196 & 0.185 & 0.177 & 0.329 & 0.328 & 0.316 & 0.313 \\
\hline & \multicolumn{8}{|c|}{$\mathrm{Na}, \mathrm{M}$} \\
\hline 2 & 2.848 & 2.800 & 2.583 & 5.391 & 3.983 & 4.035 & 4.061 & 6.565 \\
\hline 4 & 2.830 & 2.778 & 2.648 & 5.565 & 4.152 & 4.070 & 3.974 & 6.130 \\
\hline 6 & 2.930 & 2.726 & 2.639 & 5.348 & 4.052 & 4.043 & 3.926 & 6.348 \\
\hline 8 & 2.896 & 2.817 & 2.848 & 5.565 & 3.948 & 4.022 & 3.904 & 6.826 \\
\hline \multirow[t]{2}{*}{10} & 2.983 & 2.883 & 2.800 & 5.870 & 4.200 & 4.157 & 4.104 & 6.913 \\
\hline & \multicolumn{8}{|c|}{$\mathbf{P}, \mathbf{M}$} \\
\hline 2 & 0.052 & 0.055 & 0.000 & 0.000 & 0.030 & 0.031 & 0.031 & 0.000 \\
\hline 4 & 0.054 & 0.052 & 0.000 & 0.000 & 0.031 & 0.030 & 0.000 & 0.000 \\
\hline 6 & 0.048 & 0.046 & 0.000 & 0.000 & 0.028 & 0.027 & 0.000 & 0.000 \\
\hline 8 & 0.047 & 0.049 & 0.000 & 0.000 & 0.028 & 0.028 & 0.000 & 0.000 \\
\hline \multirow[t]{2}{*}{10} & 0.049 & 0.051 & 0.000 & 0.000 & 0.029 & 0.029 & 0.000 & 0.000 \\
\hline & \multicolumn{8}{|c|}{ OH, M } \\
\hline 2 & 2.500 & 2.476 & 2.565 & 2.276 & 3.629 & 3.629 & 3.629 & 3.253 \\
\hline 4 & 2.482 & 2.441 & 2.524 & 2.218 & 3.612 & 3.624 & 3.676 & 3.212 \\
\hline 6 & 2.435 & 2.382 & 2.518 & 2.229 & 3.618 & 4.424 & 3.682 & 3.094 \\
\hline 8 & 2.459 & 2.429 & 2.494 & 2.206 & 3.588 & 3.571 & 3.653 & 3.159 \\
\hline 10 & 2.447 & 2.400 & 2.500 & 2.194 & 3.559 & 3.624 & 3.624 & 3.153 \\
\hline
\end{tabular}


Table A-6. Samples ALP2-1 through ALP2-12, Concentrations in Molality.

\begin{tabular}{|c|c|c|c|c|c|c|c|c|}
\hline & 55 & 56 & 57 & 58 & 59 & 60 & 61 & 62 \\
\hline & \multicolumn{8}{|c|}{ Conversion Factors } \\
\hline $\mathrm{g}^{1}$ & 93.07 & 92.92 & 90.01 & 115.51 & 97.03 & 96.96 & 94.97 & 120.49 \\
\hline $\mathrm{mL}^{2}$ & 83.28 & 83.41 & 81.02 & 92.01 & 83.60 & 83.48 & 81.89 & 93.16 \\
\hline $\mathrm{g}^{3}$ & 81.63 & 81.63 & 80.02 & 80.01 & 81.10 & 81.10 & 80.01 & 80.01 \\
\hline $\mathrm{kg} / \mathrm{L}^{4}$ & 0.980 & 0.979 & 0.988 & 0.870 & 0.970 & 0.972 & 0.977 & 0.859 \\
\hline Week & \multicolumn{8}{|c|}{ Al, $\mathbf{m}$} \\
\hline 2 & 0.152 & 0.147 & 0.127 & 0.114 & 0.276 & 0.279 & 0.279 & 0.256 \\
\hline 4 & 0.174 & 0.176 & 0.153 & 0.151 & 0.312 & 0.310 & 0.284 & 0.276 \\
\hline 6 & 0.191 & 0.184 & 0.162 & 0.164 & 0.317 & 0.318 & 0.293 & 0.307 \\
\hline 8 & 0.196 & 0.195 & 0.187 & 0.186 & 0.321 & 0.331 & 0.308 & 0.358 \\
\hline \multirow[t]{2}{*}{10} & 0.205 & 0.201 & 0.188 & 0.204 & 0.339 & 0.338 & 0.323 & 0.365 \\
\hline & \multicolumn{8}{|c|}{$\mathrm{Na}, \mathbf{m}$} \\
\hline 2 & 2.905 & 2.861 & 2.615 & 6.200 & 4.105 & 4.153 & 4.157 & 7.644 \\
\hline 4 & 2.888 & 2.839 & 2.681 & 6.400 & 4.280 & 4.189 & 4.068 & 7.138 \\
\hline 6 & 2.990 & 2.785 & 2.672 & 6.150 & 4.177 & 4.162 & 4.019 & 7.391 \\
\hline 8 & 2.954 & 2.879 & 2.884 & 6.400 & 4.069 & 4.139 & 3.996 & 7.948 \\
\hline \multirow[t]{2}{*}{10} & 3.043 & 2.945 & 2.835 & 6.750 & 4.329 & 4.278 & 4.201 & 8.049 \\
\hline & \multicolumn{8}{|c|}{$\mathbf{P}, \mathbf{m}$} \\
\hline 2 & 0.053 & 0.056 & 0.000 & 0.000 & 0.031 & 0.032 & 0.032 & 0.000 \\
\hline 4 & 0.055 & 0.053 & 0.000 & 0.000 & 0.032 & 0.031 & 0.000 & 0.000 \\
\hline 6 & 0.049 & 0.047 & 0.000 & 0.000 & 0.029 & 0.028 & 0.000 & 0.000 \\
\hline 8 & 0.048 & 0.050 & 0.000 & 0.000 & 0.029 & 0.029 & 0.000 & 0.000 \\
\hline \multirow[t]{2}{*}{10} & 0.050 & 0.052 & 0.000 & 0.000 & 0.030 & 0.030 & 0.000 & 0.000 \\
\hline & \multicolumn{8}{|c|}{$\mathbf{O H}, \mathbf{m}$} \\
\hline 2 & 2.551 & 2.530 & 2.597 & 2.618 & 3.741 & 3.736 & 3.715 & 3.787 \\
\hline 4 & 2.533 & 2.494 & 2.555 & 2.550 & 3.723 & 3.730 & 3.763 & 3.739 \\
\hline 6 & 2.485 & 2.434 & 2.549 & 2.564 & 3.729 & 4.553 & 3.769 & 3.603 \\
\hline 8 & 2.509 & 2.482 & 2.525 & 2.537 & 3.699 & 3.675 & 3.739 & 3.678 \\
\hline 10 & 2.497 & 2.452 & 2.531 & 2.523 & 3.668 & 3.730 & 3.709 & 3.671 \\
\hline
\end{tabular}

${ }^{\mathrm{I}}$ Mass (g) of liquid phase based on mass of reagents added, assuming $25 \%$ dissolution of gibbsite, sodium phosphate, and sodium fluoride.

${ }^{2}$ Volume (mL) of liquid phase, based on calculated total mass and measured density.

${ }^{3}$ Mass (g) of $\mathrm{H}_{2} \mathrm{O}$, assuming $25 \%$ dissolution of sodium phosphate reagent.

${ }^{4}$ Mass $(\mathrm{kg})$ of $\mathrm{H}_{2} \mathrm{O}$ per $\mathrm{L}$ of liquid phase. 
LAB-RPT-13-00011 Rev 0 Appendix A

Table A-7. Analytical Results for $40^{\circ} \mathrm{C}$ Samples ALP2-21 through ALP2-27.

\begin{tabular}{|c|c|c|c|c|c|c|c|}
\hline Day & 21 & 22 & 23 & 24 & 25 & 26 & 27 \\
\hline & \multicolumn{7}{|c|}{ Density, g/mL (Undiluted Sample) } \\
\hline 1 & 1.091 & 1.125 & 1.059 & 1.211 & 1.126 & 1.133 & 1.111 \\
\hline 2 & 1.093 & 1.125 & 1.058 & 1.210 & 1.127 & 1.137 & 1.114 \\
\hline 3 & 1.095 & 1.125 & 1.058 & 1.213 & 1.128 & 1.137 & 1.115 \\
\hline 4 & 1.092 & 1.112 & 1.064 & 1.211 & 1.128 & 1.141 & 1.116 \\
\hline \multirow[t]{2}{*}{7} & 1.092 & 1.126 & 1.066 & 1.212 & 1.129 & 1.139 & 1.115 \\
\hline & \multicolumn{7}{|c|}{ Al, $\mu \mathrm{g} / \mathrm{mL}$ (Diluted Sample 10/25) } \\
\hline 1 & 1330 & 1560 & 1340 & 893 & 1960 & 2090 & 2970 \\
\hline 2 & 1700 & 1760 & 1590 & 1120 & 2940 & 2650 & 3200 \\
\hline 3 & 1830 & 1810 & 1690 & 1280 & 3380 & 3370 & 3360 \\
\hline 4 & 1850 & 1910 & 1800 & 1370 & 3760 & 3450 & 3500 \\
\hline \multirow[t]{2}{*}{7} & 2160 & 2110 & 2040 & 1590 & 3870 & 3760 & 3880 \\
\hline & \multicolumn{7}{|c|}{ Na, $\mu \mathrm{g} / \mathrm{mL}$ (Diluted Sample 10/25) } \\
\hline 1 & 18900 & 25600 & 13500 & 45600 & 31800 & 33200 & 28700 \\
\hline 2 & 19800 & 24800 & 14300 & 47300 & 31900 & 33800 & 29100 \\
\hline 3 & 20200 & 25400 & 14300 & 46900 & 30700 & 33400 & 28800 \\
\hline 4 & 19500 & 22700 & 14500 & 46500 & 32900 & 33300 & 28900 \\
\hline \multirow[t]{2}{*}{7} & 19800 & 25600 & 15100 & 47300 & 31900 & 33500 & 30500 \\
\hline & \multicolumn{7}{|c|}{ P, $\mu \mathrm{g} / \mathrm{mL}$ (Diluted Sample 10/25) } \\
\hline 1 & 2260 & 5760 & 0 & 0 & 1100 & 2140 & 0 \\
\hline 2 & 2390 & 5200 & 0 & 0 & 1170 & 2230 & 0 \\
\hline 3 & 2420 & 5390 & 0 & 0 & 1140 & 2300 & 0 \\
\hline 4 & 2270 & 4050 & 0 & 0 & 1210 & 2350 & 0 \\
\hline \multirow[t]{2}{*}{7} & 2230 & 5000 & 0 & 0 & 1170 & 2290 & 0 \\
\hline & \multicolumn{7}{|c|}{ OH, $\mu \mathrm{g} / \mathrm{mL}$ (Diluted Sample 10/25) } \\
\hline 1 & 9140 & 8670 & 9320 & 8280 & 18200 & 17400 & 17300 \\
\hline 2 & 8990 & 8520 & 9170 & 8030 & 17700 & 17100 & 17400 \\
\hline 3 & 8940 & 8560 & 9140 & 8080 & 16900 & 16600 & 17300 \\
\hline 4 & 8930 & 8740 & 8790 & 8050 & 16800 & 16300 & 17200 \\
\hline 7 & 8770 & 8700 & 9240 & 7820 & 16600 & 16200 & 17000 \\
\hline
\end{tabular}


Table A-8. Samples ALP2-21 through ALP2-27, Concentrations in Molarity.

\begin{tabular}{|c|c|c|c|c|c|c|c|}
\hline Day & 21 & 22 & 23 & 24 & 25 & 26 & 27 \\
\hline & \multicolumn{7}{|c|}{ Al, M (Undiluted Sample) } \\
\hline 1 & 0.123 & 0.144 & 0.124 & 0.083 & 0.181 & 0.194 & 0.275 \\
\hline 2 & 0.157 & 0.163 & 0.147 & 0.104 & 0.272 & 0.245 & 0.296 \\
\hline 3 & 0.169 & 0.168 & 0.156 & 0.119 & 0.313 & 0.312 & 0.311 \\
\hline 4 & 0.171 & 0.177 & 0.167 & 0.127 & 0.348 & 0.319 & 0.324 \\
\hline \multirow[t]{2}{*}{7} & 0.200 & 0.195 & 0.189 & 0.147 & 0.358 & 0.348 & 0.359 \\
\hline & \multicolumn{7}{|c|}{ Na, M (Undiluted Sample) } \\
\hline 1 & 2.054 & 2.783 & 1.467 & 4.957 & 3.457 & 3.609 & 3.120 \\
\hline 2 & 2.152 & 2.696 & 1.554 & 5.141 & 3.467 & 3.674 & 3.163 \\
\hline 3 & 2.196 & 2.761 & 1.554 & 5.098 & 3.337 & 3.630 & 3.130 \\
\hline 4 & 2.120 & 2.467 & 1.576 & 5.054 & 3.576 & 3.620 & 3.141 \\
\hline \multirow[t]{2}{*}{7} & 2.152 & 2.783 & 1.641 & 5.141 & 3.467 & 3.641 & 3.315 \\
\hline & \multicolumn{7}{|c|}{ P, M (Undiluted Sample) } \\
\hline 1 & 0.182 & 0.465 & 0.000 & 0.000 & 0.089 & 0.173 & 0.000 \\
\hline 2 & 0.193 & 0.419 & 0.000 & 0.000 & 0.094 & 0.180 & 0.000 \\
\hline 3 & 0.195 & 0.435 & 0.000 & 0.000 & 0.092 & 0.185 & 0.000 \\
\hline 4 & 0.183 & 0.327 & 0.000 & 0.000 & 0.098 & 0.190 & 0.000 \\
\hline \multirow[t]{2}{*}{7} & 0.180 & 0.403 & 0.000 & 0.000 & 0.094 & 0.185 & 0.000 \\
\hline & \multicolumn{7}{|c|}{ OH, M (Undiluted Sample) } \\
\hline 1 & 1.344 & 1.275 & 1.371 & 1.218 & 2.676 & 2.559 & 2.544 \\
\hline 2 & 1.322 & 1.253 & 1.349 & 1.181 & 2.603 & 2.515 & 2.559 \\
\hline 3 & 1.315 & 1.259 & 1.344 & 1.188 & 2.485 & 2.441 & 2.544 \\
\hline 4 & 1.313 & 1.285 & 1.293 & 1.184 & 2.471 & 2.397 & 2.529 \\
\hline 7 & 1.290 & 1.279 & 1.359 & 1.150 & 2.441 & 2.382 & 2.500 \\
\hline
\end{tabular}


Table A-9. Samples ALP2-21 through ALP2-27, Concentrations in Molality.

\begin{tabular}{|c|c|c|c|c|c|c|c|}
\hline & 21 & 22 & 23 & 24 & 25 & 26 & 27 \\
\hline & \multicolumn{7}{|c|}{ Conversion Factors } \\
\hline $\mathrm{g}^{1}$ & 95.37 & 95.02 & 87.23 & 112.73 & 101.76 & 101.34 & 93.53 \\
\hline $\mathrm{mL}^{2}$ & 87.44 & 84.42 & 82.34 & 93.10 & 90.39 & 89.42 & 84.20 \\
\hline $\mathrm{g}^{3}$ & 84.32 & 84.33 & 80.00 & 80.01 & 84.34 & 84.33 & 80.02 \\
\hline $\mathrm{kg} / \mathrm{L}^{4}$ & 0.964 & 0.999 & 0.972 & 0.859 & 0.933 & 0.943 & 0.950 \\
\hline Day & \multicolumn{7}{|c|}{ Al, m (Undiluted Sample) } \\
\hline 1 & 0.128 & 0.145 & 0.128 & 0.096 & 0.194 & 0.205 & 0.289 \\
\hline 2 & 0.163 & 0.163 & 0.152 & 0.121 & 0.292 & 0.260 & 0.312 \\
\hline 3 & 0.176 & 0.168 & 0.161 & 0.138 & 0.335 & 0.331 & 0.327 \\
\hline 4 & 0.178 & 0.177 & 0.172 & 0.148 & 0.373 & 0.339 & 0.341 \\
\hline \multirow[t]{2}{*}{7} & 0.207 & 0.196 & 0.194 & 0.171 & 0.384 & 0.369 & 0.378 \\
\hline & \multicolumn{7}{|c|}{ Na, m (Undiluted Sample) } \\
\hline 1 & 2.130 & 2.786 & 1.510 & 5.768 & 3.704 & 3.827 & 3.283 \\
\hline 2 & 2.232 & 2.699 & 1.600 & 5.983 & 3.716 & 3.896 & 3.328 \\
\hline 3 & 2.277 & 2.764 & 1.600 & 5.932 & 3.576 & 3.850 & 3.294 \\
\hline 4 & 2.198 & 2.470 & 1.622 & 5.881 & 3.833 & 3.838 & 3.306 \\
\hline \multirow[t]{2}{*}{7} & 2.232 & 2.786 & 1.689 & 5.983 & 3.716 & 3.861 & 3.489 \\
\hline & \multicolumn{7}{|c|}{ P, m (Undiluted Sample) } \\
\hline 1 & 0.189 & 0.465 & 0.000 & 0.000 & 0.095 & 0.183 & 0.000 \\
\hline 2 & 0.200 & 0.420 & 0.000 & 0.000 & 0.101 & 0.191 & 0.000 \\
\hline 3 & 0.202 & 0.435 & 0.000 & 0.000 & 0.099 & 0.197 & 0.000 \\
\hline 4 & 0.190 & 0.327 & 0.000 & 0.000 & 0.105 & 0.201 & 0.000 \\
\hline \multirow[t]{2}{*}{7} & 0.186 & 0.404 & 0.000 & 0.000 & 0.101 & 0.196 & 0.000 \\
\hline & \multicolumn{7}{|c|}{ OH, m (Undiluted Sample) } \\
\hline 1 & 1.394 & 1.276 & 1.411 & 1.417 & 2.868 & 2.713 & 2.677 \\
\hline 2 & 1.371 & 1.254 & 1.388 & 1.374 & 2.790 & 2.667 & 2.693 \\
\hline 3 & 1.363 & 1.260 & 1.383 & 1.383 & 2.664 & 2.589 & 2.677 \\
\hline 4 & 1.362 & 1.287 & 1.330 & 1.378 & 2.648 & 2.542 & 2.662 \\
\hline 7 & 1.337 & 1.281 & 1.398 & 1.338 & 2.616 & 2.526 & 2.631 \\
\hline
\end{tabular}

${ }^{\mathrm{I}}$ Mass (g) of liquid phase based on mass of reagents added, assuming 25\% dissolution of gibbsite, sodium phosphate, and sodium fluoride.

${ }^{2}$ Volume $(\mathrm{mL})$ of liquid phase, based on calculated total mass and measured density.

${ }^{3}$ Mass (g) of $\mathrm{H}_{2} \mathrm{O}$, assuming $25 \%$ dissolution of sodium phosphate reagent.

${ }^{4}$ Mass (kg) of $\mathrm{H}_{2} \mathrm{O}$ per L of liquid phase. 
LAB-RPT-13-00011 Rev 0 Appendix A

Table A-10. Analytical Results for $40{ }^{\circ} \mathrm{C}$ Samples ALP2-28 through ALP2-47.

\begin{tabular}{|c|c|c|c|c|c|c|c|c|c|c|c|c|c|}
\hline Day & 28 & 29 & 30 & 31 & 32 & Day & 41 & 42 & 43 & 44 & 45 & 46 & 47 \\
\hline & \multicolumn{13}{|c|}{ Density, g/mL (Undiluted Sample) } \\
\hline 1 & 1.252 & 1.171 & 1.174 & 1.160 & 1.293 & 1 & 1.086 & 1.120 & 1.060 & 1.213 & 1.120 & 1.136 & 1.117 \\
\hline 4 & 1.258 & 1.172 & 1.179 & 1.167 & 1.296 & 5 & 1.090 & 1.127 & 1.060 & 1.216 & 1.130 & 1.138 & 1.119 \\
\hline 7 & 1.256 & 1.174 & 1.183 & 1.170 & 1.300 & 7 & 1.091 & 1.126 & 1.061 & 1.214 & 1.127 & 1.138 & 1.118 \\
\hline 10 & 1.254 & 1.177 & 1.182 & 1.169 & 1.301 & 9 & 1.092 & 1.126 & 1.060 & 1.212 & 1.130 & 1.143 & 1.113 \\
\hline \multirow[t]{2}{*}{14} & 1.248 & 1.176 & 1.178 & 1.171 & 1.298 & 14 & 1.095 & 1.124 & 1.061 & 1.215 & 1.130 & 1.142 & 1.120 \\
\hline & \multicolumn{13}{|c|}{ Al, $\mu \mathrm{g} / \mathrm{mL}$ (Diluted Sample 10/25) } \\
\hline 1 & 1990 & 5130 & 5210 & 4710 & 4460 & 1 & 571 & 565 & 1240 & 705 & 1600 & 2260 & 4670 \\
\hline 4 & 3160 & 5600 & 5850 & 5790 & 5830 & 5 & 1360 & 1600 & 1510 & 1360 & 3200 & 3490 & 3820 \\
\hline 7 & 3540 & 6310 & 6070 & 6090 & 6220 & 7 & 1630 & 1650 & 1590 & 1450 & 3490 & 3640 & 4720 \\
\hline 10 & 3810 & 6530 & 6290 & 6330 & 6520 & 9 & 1720 & 1680 & 1640 & 1510 & 3660 & 3700 & 4680 \\
\hline \multirow[t]{2}{*}{14} & 3700 & 6450 & 6430 & 6440 & 6800 & 14 & 1810 & 1690 & 1700 & 1660 & 3750 & 3720 & 4670 \\
\hline & \multicolumn{13}{|c|}{ Na, $\mu \mathrm{g} / \mathrm{mL}$ (Diluted Sample 10/25) } \\
\hline 1 & 56100 & 41800 & 41900 & 41200 & 67600 & 1 & 19100 & 25000 & 13300 & 45300 & 27900 & 31400 & 26900 \\
\hline 4 & 56600 & 43200 & 43600 & 41300 & 66000 & 5 & 19400 & 24600 & 13500 & 44200 & 29700 & 31900 & 22100 \\
\hline 7 & 55300 & 42300 & 43000 & 37100 & 63500 & 7 & 19700 & 25900 & 13800 & 43000 & 29700 & 31300 & 27300 \\
\hline 10 & 52800 & 40200 & 39800 & 36900 & 60800 & 9 & 19600 & 25500 & 13700 & 42100 & 29800 & 30800 & 27100 \\
\hline \multirow[t]{2}{*}{14} & 50500 & 40200 & 40700 & 38600 & 61900 & 14 & 19700 & 24900 & 13700 & 42200 & 29400 & 30100 & 27200 \\
\hline & \multicolumn{13}{|c|}{ P, $\mu \mathrm{g} / \mathrm{mL}$ (Diluted Sample 10/25) } \\
\hline 1 & 0 & 772 & 1290 & 0 & 0 & 1 & 1940 & 5400 & 0 & 0 & 989 & 2430 & 0 \\
\hline 4 & 0 & 986 & 1660 & 0 & 0 & 5 & 2320 & 5350 & 0 & 0 & 1290 & 2440 & 0 \\
\hline 7 & 0 & 957 & 1600 & 0 & 0 & 7 & 2390 & 5550 & 0 & 0 & 1310 & 2500 & 0 \\
\hline 10 & 0 & 912 & 1510 & 0 & 0 & 9 & 2330 & 5430 & 0 & 0 & 1290 & 2460 & 0 \\
\hline \multirow[t]{2}{*}{14} & 0 & 918 & 1600 & 0 & 0 & 14 & 2340 & 5380 & 0 & 0 & 1280 & 2420 & 0 \\
\hline & \multicolumn{13}{|c|}{ OH, $\mu \mathrm{g} / \mathrm{mL}$ (Diluted Sample 10/25) } \\
\hline 1 & 15600 & 24400 & 23800 & 25200 & 21800 & 1 & 9480 & 8960 & 9170 & 8550 & 17800 & 16900 & 16400 \\
\hline 4 & 14900 & 23800 & 23400 & 24500 & 20000 & 5 & 9000 & 8300 & 9000 & 8350 & 17000 & 16300 & 16500 \\
\hline 7 & 14700 & 23500 & 22900 & 23000 & 19700 & 7 & 8830 & 8260 & 8920 & 7930 & 16700 & 16000 & 16300 \\
\hline 10 & 14300 & 23600 & 23300 & 24200 & 20500 & 9 & 8670 & 8530 & 8930 & 7950 & 17000 & 16000 & 16300 \\
\hline 14 & 13800 & 23400 & 22900 & 24100 & 20200 & 14 & 8680 & 8100 & 8870 & 7810 & 16700 & 16000 & 16400 \\
\hline
\end{tabular}


LAB-RPT-13-00011 Rev 0 Appendix A

Table A-11. Samples ALP2-28 through ALP2-47, Concentrations in Molarity.

\begin{tabular}{|c|c|c|c|c|c|c|c|c|c|c|c|c|c|}
\hline Day & 28 & 29 & 30 & 31 & 32 & Day & 41 & 42 & 43 & 44 & 45 & 46 & 47 \\
\hline & \multicolumn{13}{|c|}{ Al, M (Undiluted Sample) } \\
\hline 1 & 0.184 & 0.475 & 0.482 & 0.436 & 0.413 & 1 & 0.053 & 0.052 & 0.115 & 0.065 & 0.148 & 0.209 & 0.432 \\
\hline 4 & 0.293 & 0.519 & 0.542 & 0.536 & 0.540 & 5 & 0.126 & 0.148 & 0.140 & 0.126 & 0.296 & 0.323 & 0.354 \\
\hline 7 & 0.328 & 0.584 & 0.562 & 0.564 & 0.576 & 7 & 0.151 & 0.153 & 0.147 & 0.134 & 0.323 & 0.337 & 0.437 \\
\hline 10 & 0.353 & 0.605 & 0.582 & 0.586 & 0.604 & 9 & 0.159 & 0.156 & 0.152 & 0.140 & 0.339 & 0.343 & 0.433 \\
\hline \multirow[t]{2}{*}{14} & 0.343 & 0.597 & 0.595 & 0.596 & 0.630 & 14 & 0.168 & 0.156 & 0.157 & 0.154 & 0.347 & 0.344 & 0.432 \\
\hline & \multicolumn{13}{|c|}{ Na, M (Undiluted Sample) } \\
\hline 1 & 6.098 & 4.543 & 4.554 & 4.478 & 7.348 & 1 & 2.076 & 2.717 & 1.446 & 4.924 & 3.033 & 3.413 & 2.924 \\
\hline 4 & 6.152 & 4.696 & 4.739 & 4.489 & 7.174 & 5 & 2.109 & 2.674 & 1.467 & 4.804 & 3.228 & 3.467 & 2.402 \\
\hline 7 & 6.011 & 4.598 & 4.674 & 4.033 & 6.902 & 7 & 2.141 & 2.815 & 1.500 & 4.674 & 3.228 & 3.402 & 2.967 \\
\hline 10 & 5.739 & 4.370 & 4.326 & 4.011 & 6.609 & 9 & 2.130 & 2.772 & 1.489 & 4.576 & 3.239 & 3.348 & 2.946 \\
\hline \multirow[t]{2}{*}{14} & 5.489 & 4.370 & 4.424 & 4.196 & 6.728 & 14 & 2.141 & 2.707 & 1.489 & 4.587 & 3.196 & 3.272 & 2.957 \\
\hline & \multicolumn{13}{|c|}{ P, M (Undiluted Sample) } \\
\hline 1 & 0.000 & 0.062 & 0.104 & 0.000 & 0.000 & 1 & 0.156 & 0.435 & 0.000 & 0.000 & 0.080 & 0.196 & 0.000 \\
\hline 4 & 0.000 & 0.080 & 0.134 & 0.000 & 0.000 & 5 & 0.187 & 0.431 & 0.000 & 0.000 & 0.104 & 0.197 & 0.000 \\
\hline 7 & 0.000 & 0.077 & 0.129 & 0.000 & 0.000 & 7 & 0.193 & 0.448 & 0.000 & 0.000 & 0.106 & 0.202 & 0.000 \\
\hline 10 & 0.000 & 0.074 & 0.122 & 0.000 & 0.000 & 9 & 0.188 & 0.438 & 0.000 & 0.000 & 0.104 & 0.198 & 0.000 \\
\hline \multirow[t]{2}{*}{14} & 0.000 & 0.074 & 0.129 & 0.000 & 0.000 & 14 & 0.189 & 0.434 & 0.000 & 0.000 & 0.103 & 0.195 & 0.000 \\
\hline & \multicolumn{13}{|c|}{ OH, M (Undiluted Sample) } \\
\hline 1 & 2.294 & 3.588 & 3.500 & 3.706 & 3.206 & 1 & 1.394 & 1.318 & 1.349 & 1.257 & 2.618 & 2.485 & 2.412 \\
\hline 4 & 2.191 & 3.500 & 3.441 & 3.603 & 2.941 & 5 & 1.324 & 1.221 & 1.324 & 1.228 & 2.500 & 2.397 & 2.426 \\
\hline 7 & 2.162 & 3.456 & 3.368 & 3.382 & 2.897 & 7 & 1.299 & 1.215 & 1.312 & 1.166 & 2.456 & 2.353 & 2.397 \\
\hline 10 & 2.103 & 3.471 & 3.426 & 3.559 & 3.015 & 9 & 1.275 & 1.254 & 1.313 & 1.169 & 2.500 & 2.353 & 2.397 \\
\hline 14 & 2.029 & 3.441 & 3.368 & 3.544 & 2.971 & 14 & 1.276 & 1.191 & 1.304 & 1.149 & 2.456 & 2.353 & 2.412 \\
\hline
\end{tabular}


LAB-RPT-13-00011 Rev 0

Appendix A

Table A-12. Samples ALP2-28 through ALP2-47, Concentrations in Molality.

\begin{tabular}{|c|c|c|c|c|c|c|c|c|c|c|c|c|c|}
\hline Day & 28 & 29 & 30 & 31 & 32 & Day & 41 & 42 & 43 & 44 & 45 & 46 & 47 \\
\hline & \multicolumn{13}{|c|}{ Conversion Factors } \\
\hline $\mathrm{g}^{1}$ & 119.0 & 108.1 & 107.7 & 99.9 & 125.4 & -- & 95.4 & 95.0 & 87.2 & 112.7 & 101.8 & 101.3 & 93.5 \\
\hline $\mathrm{mL}^{2}$ & 95.1 & 92.3 & 91.7 & 86.1 & 97.0 & - & 87.9 & 84.8 & 82.3 & 92.9 & 90.9 & 89.1 & 83.7 \\
\hline $\mathrm{g}^{3}$ & 80.0 & 84.3 & 84.3 & 80.0 & 80.0 & -- & 84.3 & 84.3 & 80.0 & 80.0 & 84.3 & 84.3 & 80.0 \\
\hline \multirow[t]{2}{*}{$\mathrm{kg} / \mathrm{L}^{4}$} & 0.842 & 0.914 & 0.920 & 0.929 & 0.825 & -- & 0.959 & 0.994 & 0.972 & 0.861 & 0.928 & 0.946 & 0.956 \\
\hline & \multicolumn{13}{|c|}{ Al, m (Undiluted Sample) } \\
\hline 1 & 0.219 & 0.520 & 0.524 & 0.469 & 0.501 & 1 & 0.055 & 0.053 & 0.118 & 0.076 & 0.160 & 0.221 & 0.453 \\
\hline 4 & 0.348 & 0.568 & 0.589 & 0.577 & 0.655 & 5 & 0.131 & 0.149 & 0.144 & 0.146 & 0.319 & 0.342 & 0.370 \\
\hline 7 & 0.389 & 0.640 & 0.611 & 0.607 & 0.698 & 7 & 0.157 & 0.154 & 0.151 & 0.156 & 0.348 & 0.356 & 0.457 \\
\hline 10 & 0.419 & 0.662 & 0.633 & 0.631 & 0.732 & 9 & 0.166 & 0.156 & 0.156 & 0.162 & 0.365 & 0.362 & 0.453 \\
\hline \multirow[t]{2}{*}{14} & 0.407 & 0.654 & 0.647 & 0.642 & 0.763 & 14 & 0.175 & 0.157 & 0.162 & 0.179 & 0.374 & 0.364 & 0.453 \\
\hline & \multicolumn{13}{|c|}{ Na, m (Undiluted Sample) } \\
\hline 1 & 7.246 & 4.974 & 4.952 & 4.819 & 8.909 & 1 & 2.164 & 2.733 & 1.487 & 5.719 & 3.268 & 3.608 & 3.060 \\
\hline 4 & 7.310 & 5.140 & 5.153 & 4.831 & 8.698 & 5 & 2.198 & 2.689 & 1.509 & 5.580 & 3.479 & 3.665 & 2.514 \\
\hline 7 & 7.143 & 5.033 & 5.082 & 4.340 & 8.369 & 7 & 2.232 & 2.831 & 1.542 & 5.428 & 3.479 & 3.596 & 3.105 \\
\hline 10 & 6.820 & 4.783 & 4.704 & 4.316 & 8.013 & 9 & 2.220 & 2.787 & 1.531 & 5.315 & 3.491 & 3.539 & 3.083 \\
\hline \multirow[t]{2}{*}{14} & 6.523 & 4.783 & 4.810 & 4.515 & 8.158 & 14 & 2.232 & 2.722 & 1.531 & 5.327 & 3.444 & 3.458 & 3.094 \\
\hline & \multicolumn{13}{|c|}{ P, m (Undiluted Sample) } \\
\hline 1 & 0.000 & 0.068 & 0.113 & 0.000 & 0.000 & 1 & 0.163 & 0.438 & 0.000 & 0.000 & 0.086 & 0.207 & 0.000 \\
\hline 4 & 0.000 & 0.087 & 0.146 & 0.000 & 0.000 & 5 & 0.195 & 0.434 & 0.000 & 0.000 & 0.112 & 0.208 & 0.000 \\
\hline 7 & 0.000 & 0.084 & 0.140 & 0.000 & 0.000 & 7 & 0.201 & 0.450 & 0.000 & 0.000 & 0.114 & 0.213 & 0.000 \\
\hline 10 & 0.000 & 0.081 & 0.132 & 0.000 & 0.000 & 9 & 0.196 & 0.440 & 0.000 & 0.000 & 0.112 & 0.210 & 0.000 \\
\hline \multirow[t]{2}{*}{14} & 0.000 & 0.081 & 0.140 & 0.000 & 0.000 & 14 & 0.197 & 0.436 & 0.000 & 0.000 & 0.111 & 0.206 & 0.000 \\
\hline & \multicolumn{13}{|c|}{ OH, m (Undiluted Sample) } \\
\hline 1 & 2.726 & 3.928 & 3.805 & 3.988 & 3.887 & 1 & 1.453 & 1.325 & 1.387 & 1.460 & 2.821 & 2.627 & 2.524 \\
\hline 4 & 2.604 & 3.831 & 3.741 & 3.877 & 3.566 & 5 & 1.379 & 1.227 & 1.361 & 1.426 & 2.694 & 2.534 & 2.539 \\
\hline 7 & 2.569 & 3.783 & 3.661 & 3.640 & 3.513 & 7 & 1.353 & 1.222 & 1.349 & 1.354 & 2.647 & 2.487 & 2.509 \\
\hline 10 & 2.499 & 3.799 & 3.725 & 3.830 & 3.655 & 9 & 1.329 & 1.262 & 1.350 & 1.358 & 2.694 & 2.487 & 2.509 \\
\hline 14 & 2.411 & 3.767 & 3.661 & 3.814 & 3.602 & 14 & 1.330 & 1.198 & 1.341 & 1.334 & 2.647 & 2.487 & 2.524 \\
\hline
\end{tabular}

${ }^{\mathrm{I}}$ Mass $(\mathrm{g})$ of liquid phase based on mass of reagents added, assuming $25 \%$ dissolution of gibbsite, sodium phosphate, and sodium

fluoride.

${ }^{2}$ Volume (mL) of liquid phase, based on calculated total mass and measured density.

${ }^{3}$ Mass (g) of $\mathrm{H}_{2} \mathrm{O}$, assuming $25 \%$ dissolution of sodium phosphate reagent.

${ }^{4}$ Mass $(\mathrm{kg})$ of $\mathrm{H}_{2} \mathrm{O}$ per $\mathrm{L}$ of liquid phase. 


\section{APPENDIX B}

Gibbsite Dissolution Rate Plots 
LAB-RPT-13-00011 Rev 0 Appendix B

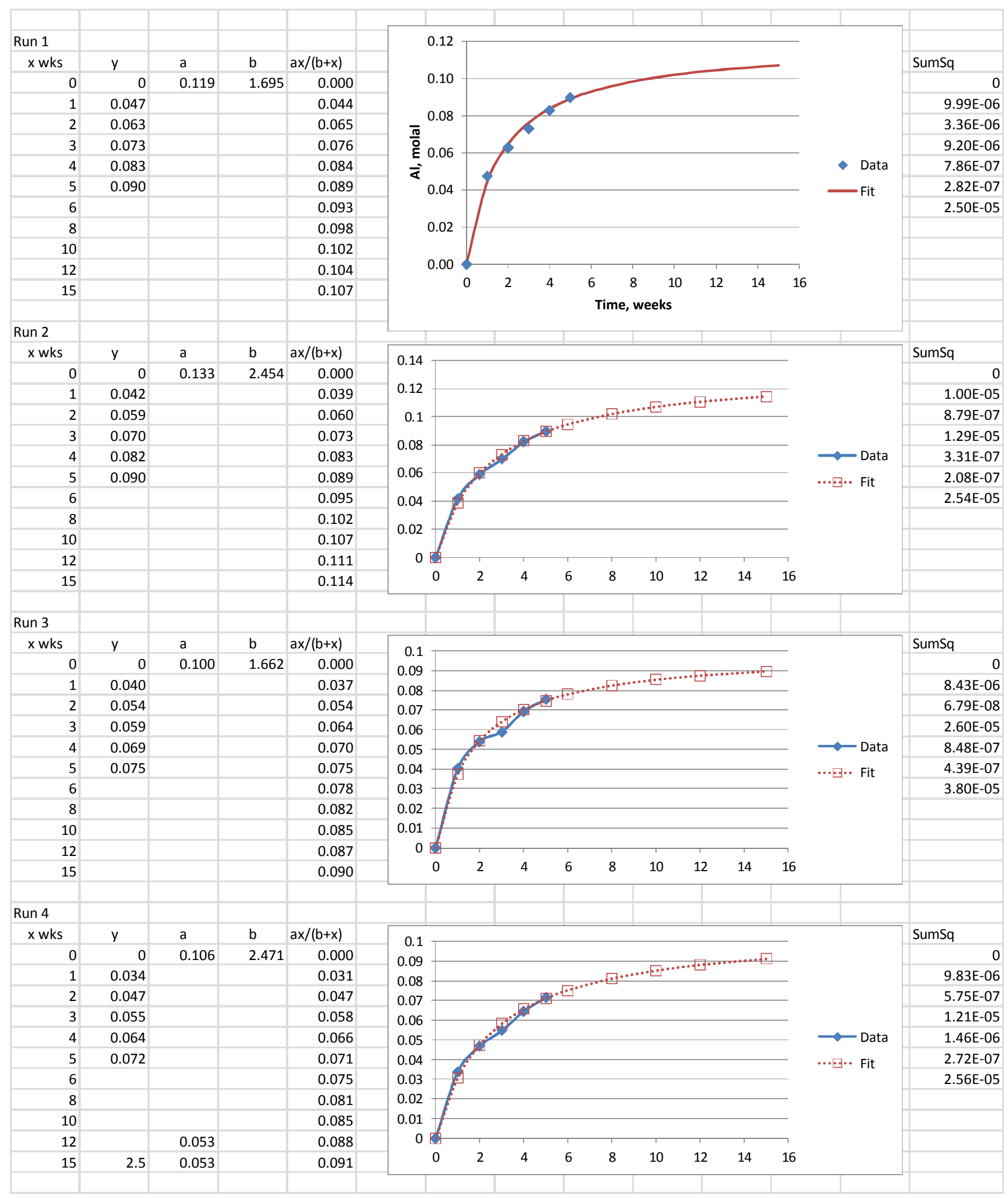


LAB-RPT-13-00011 Rev 0

Appendix B

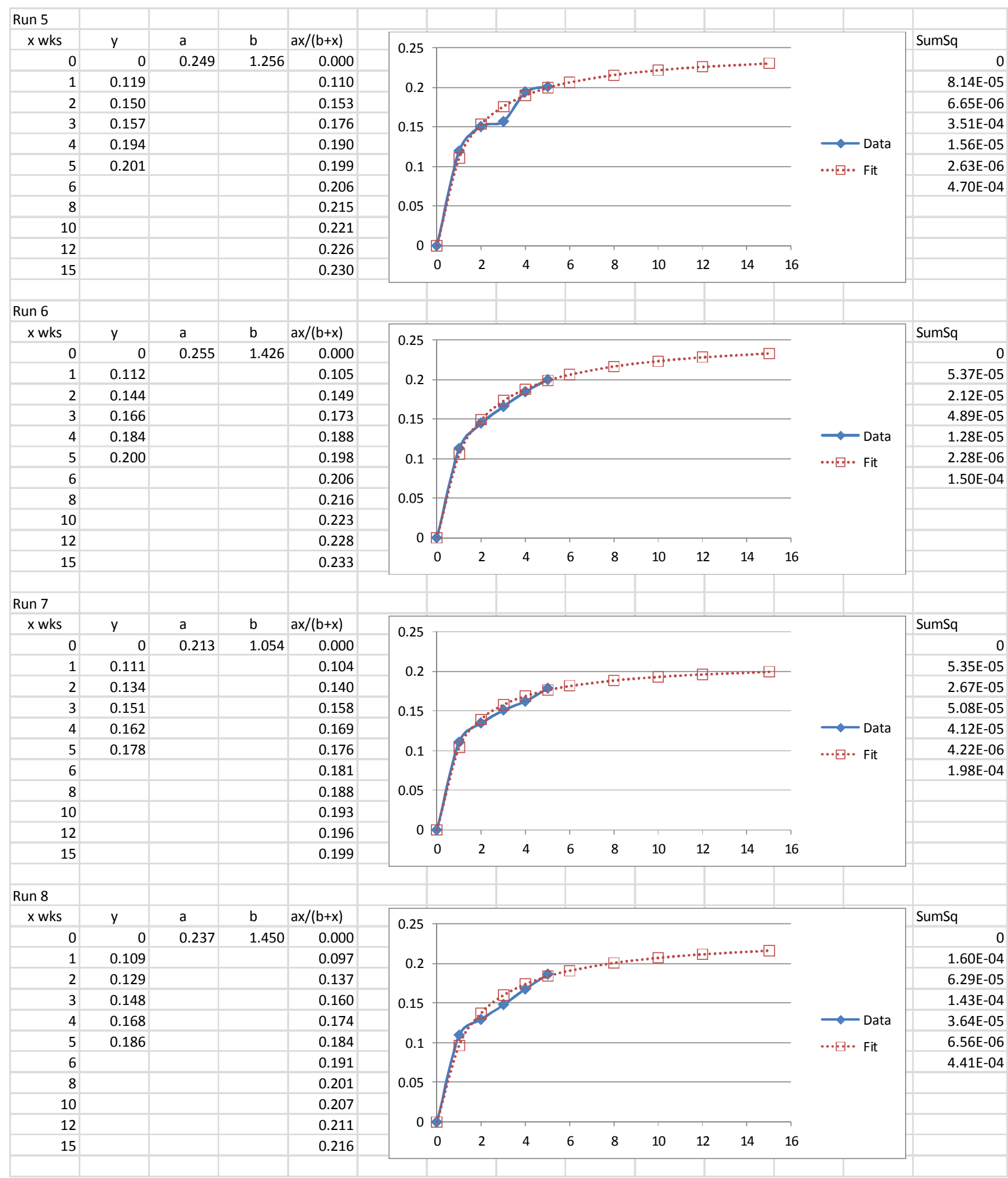


LAB-RPT-13-00011 Rev 0 Appendix B

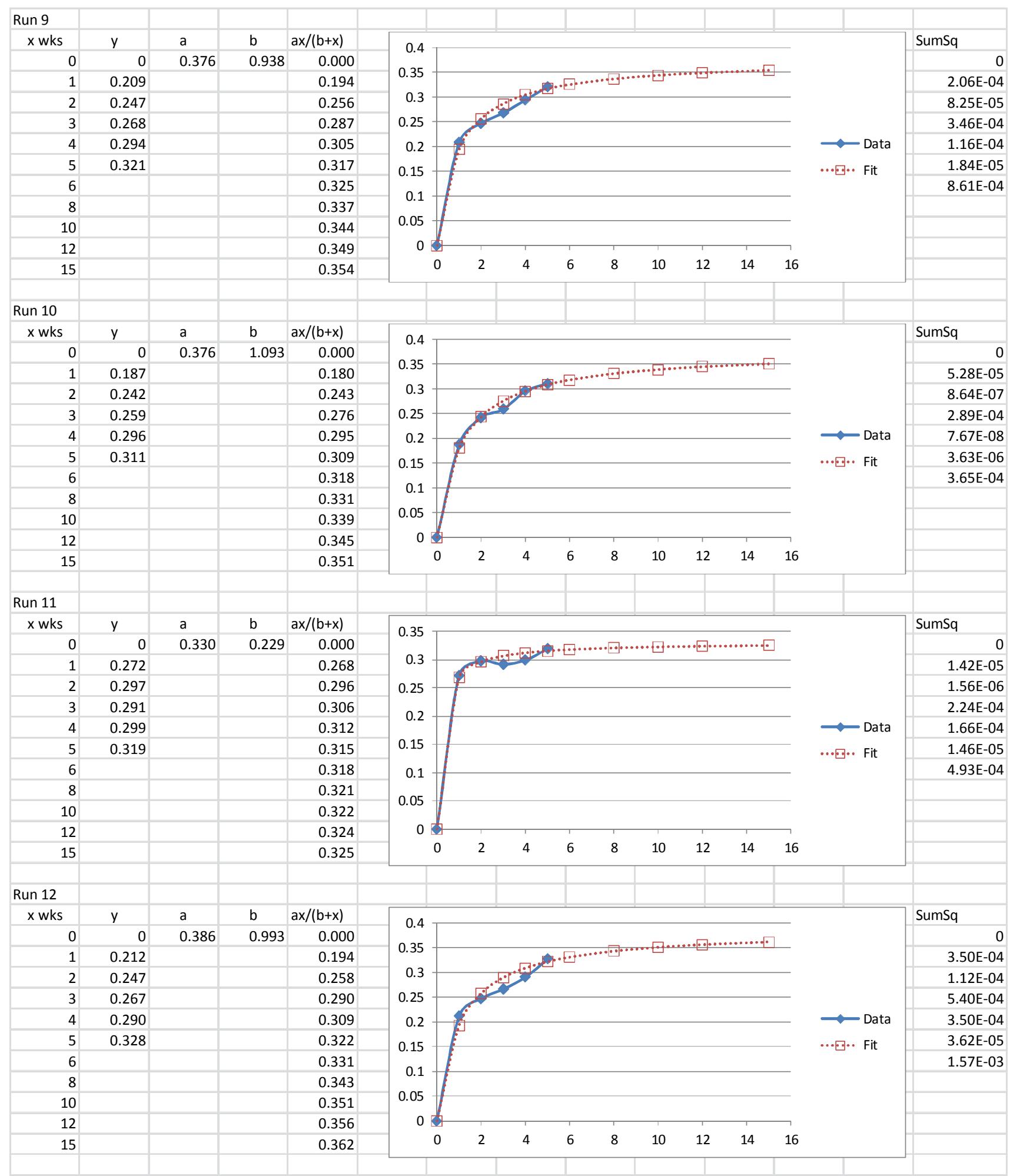


LAB-RPT-13-00011 Rev 0 Appendix B

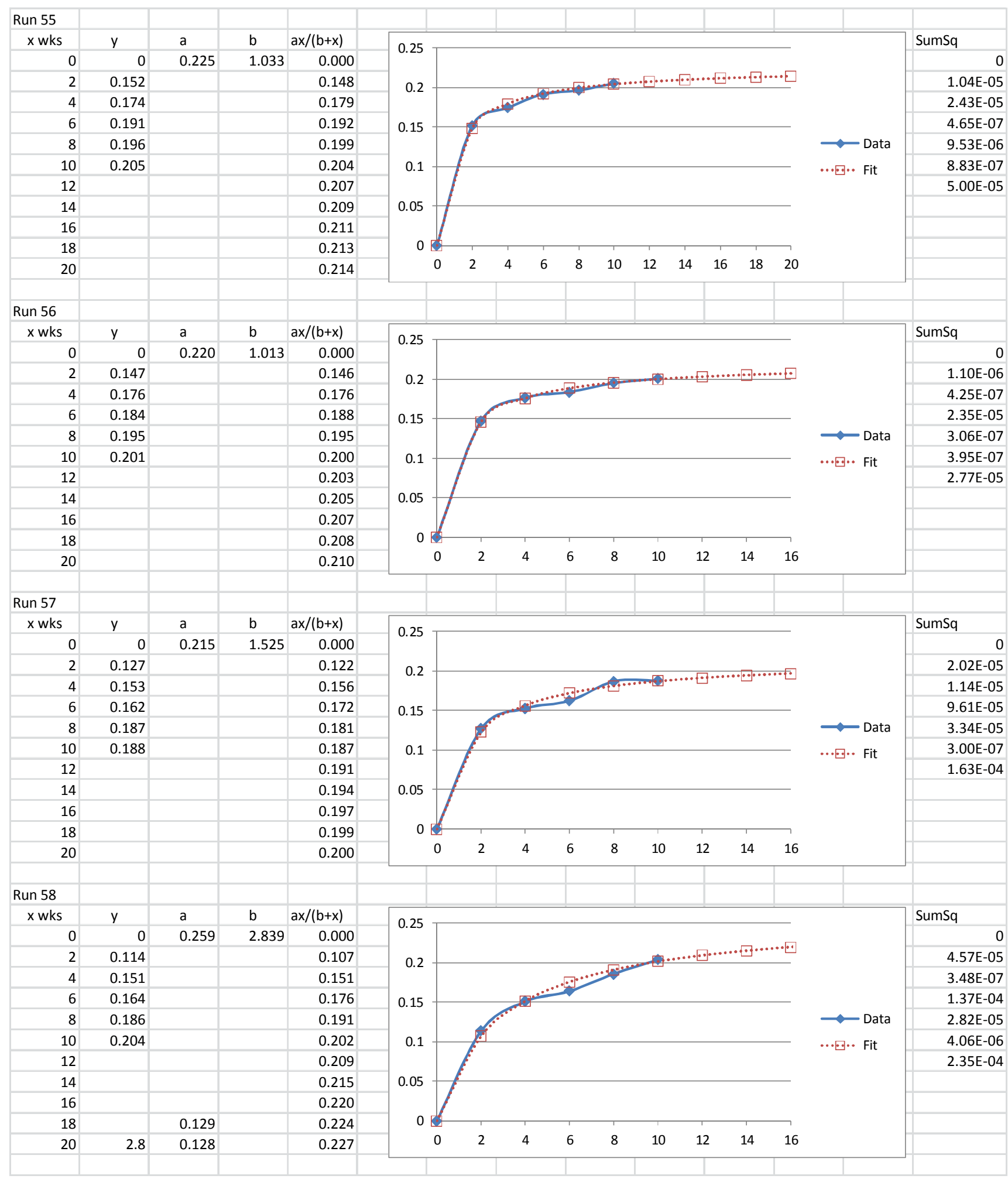


LAB-RPT-13-00011 Rev 0 Appendix B

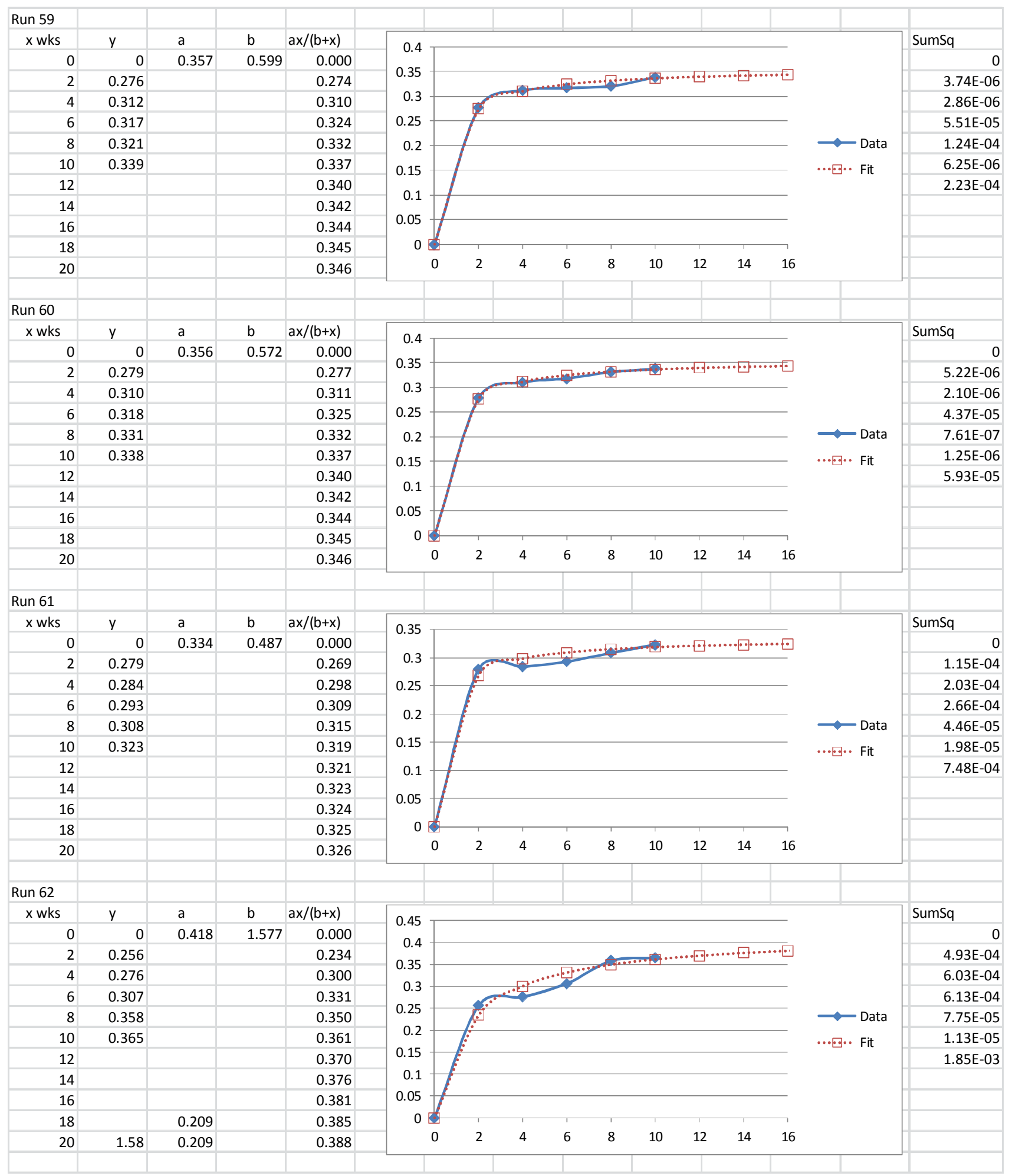


LAB-RPT-13-00011 Rev 0

Appendix B

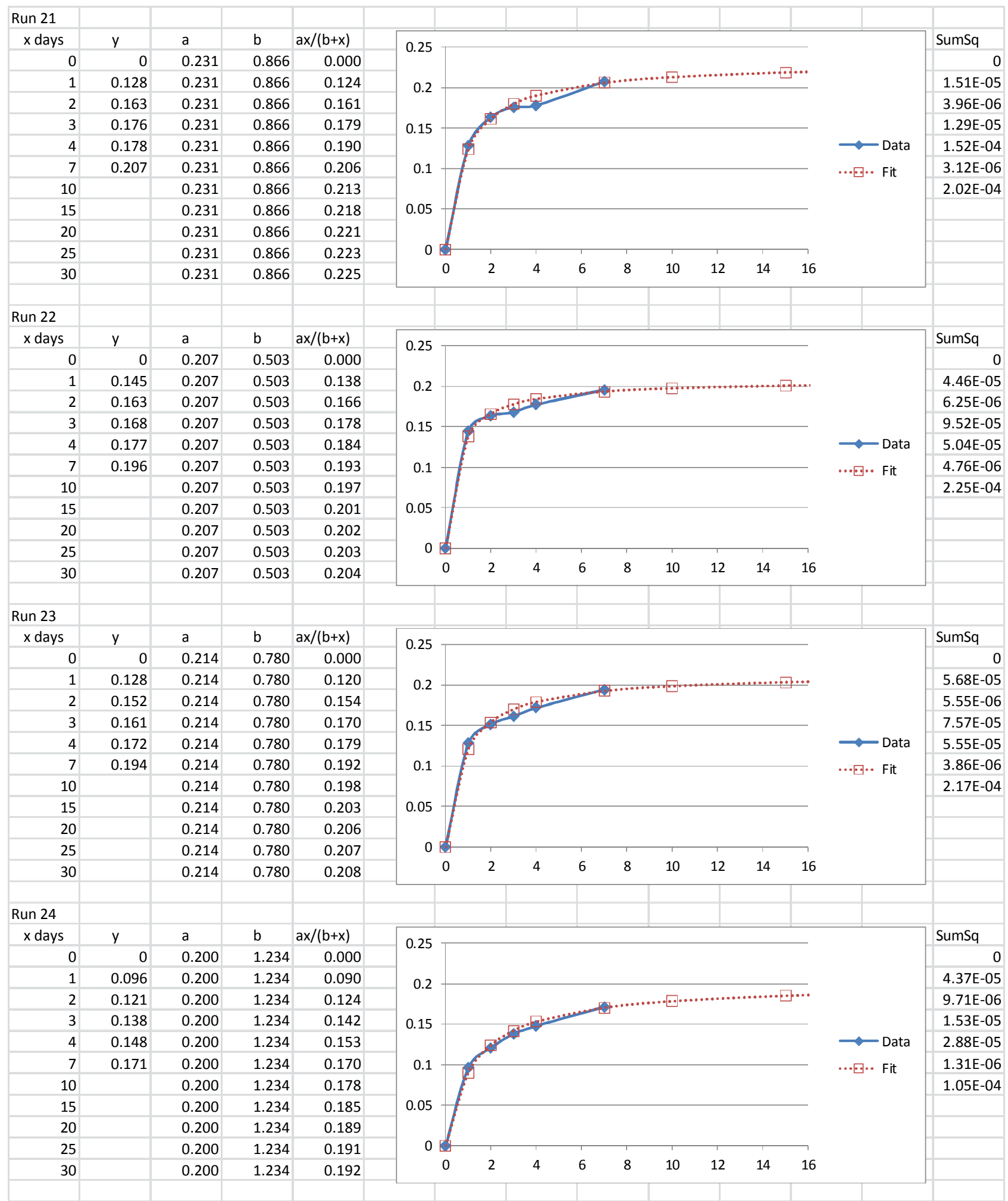


LAB-RPT-13-00011 Rev 0

Appendix B

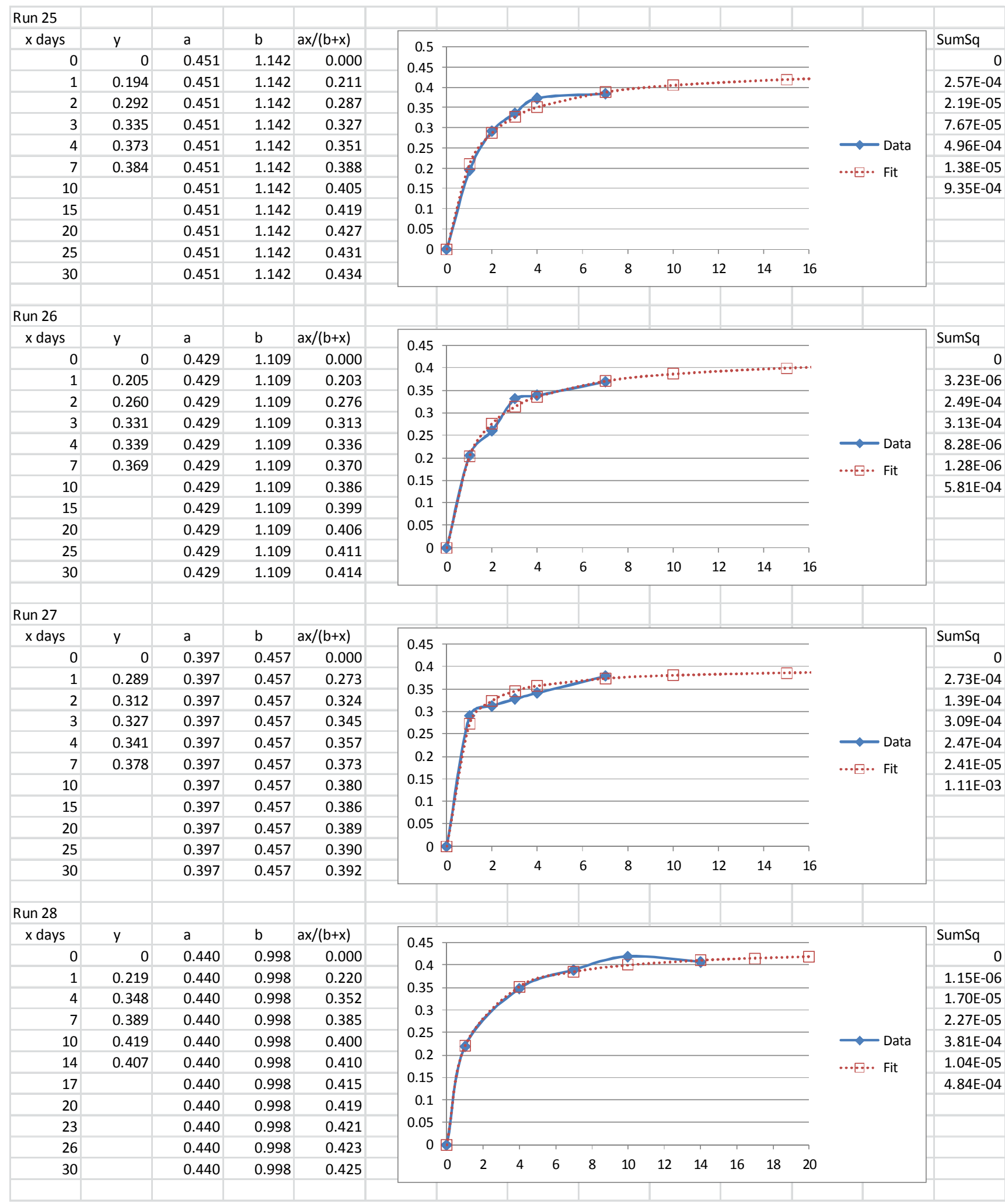




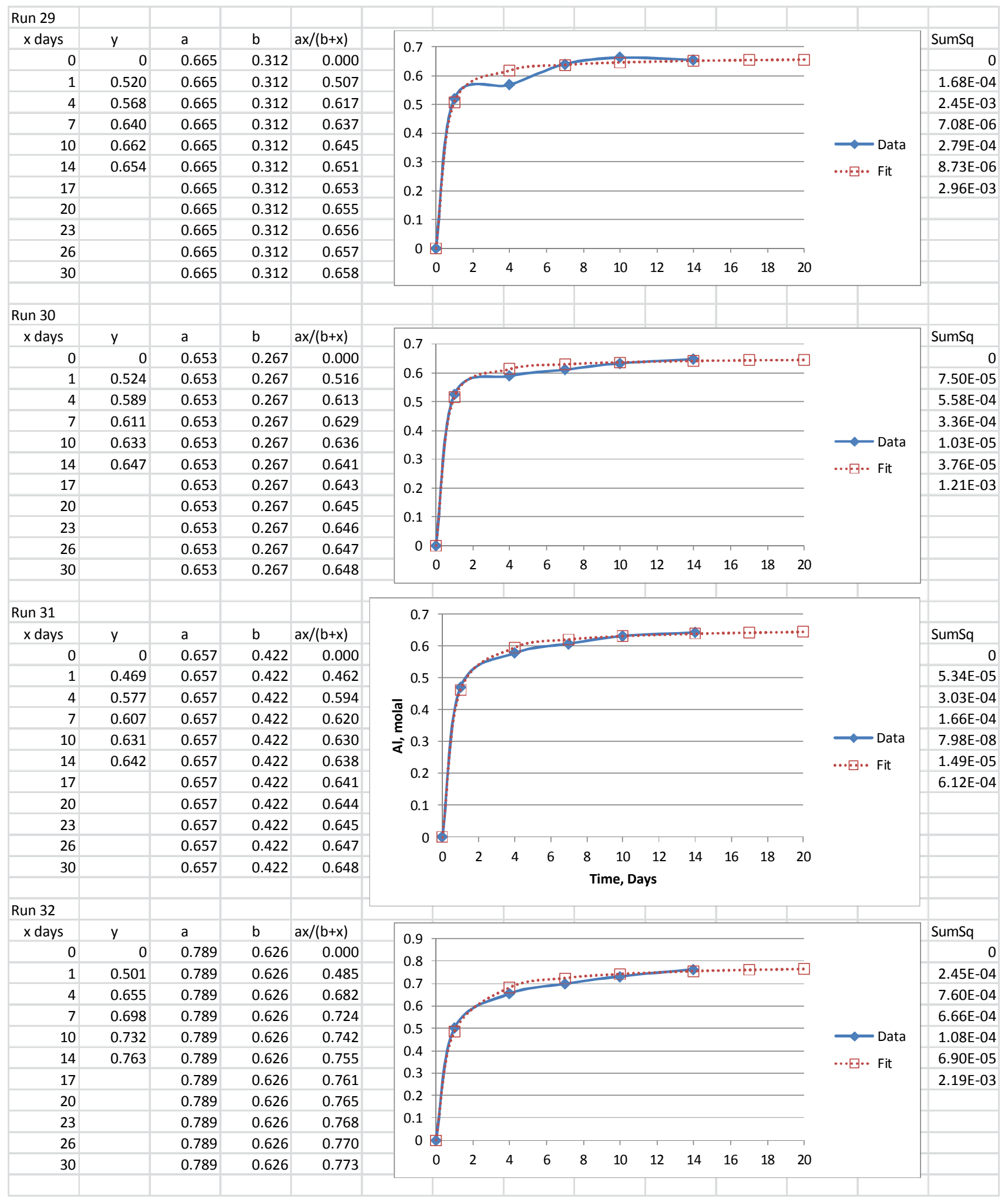


LAB-RPT-13-00011 Rev 0

Appendix B

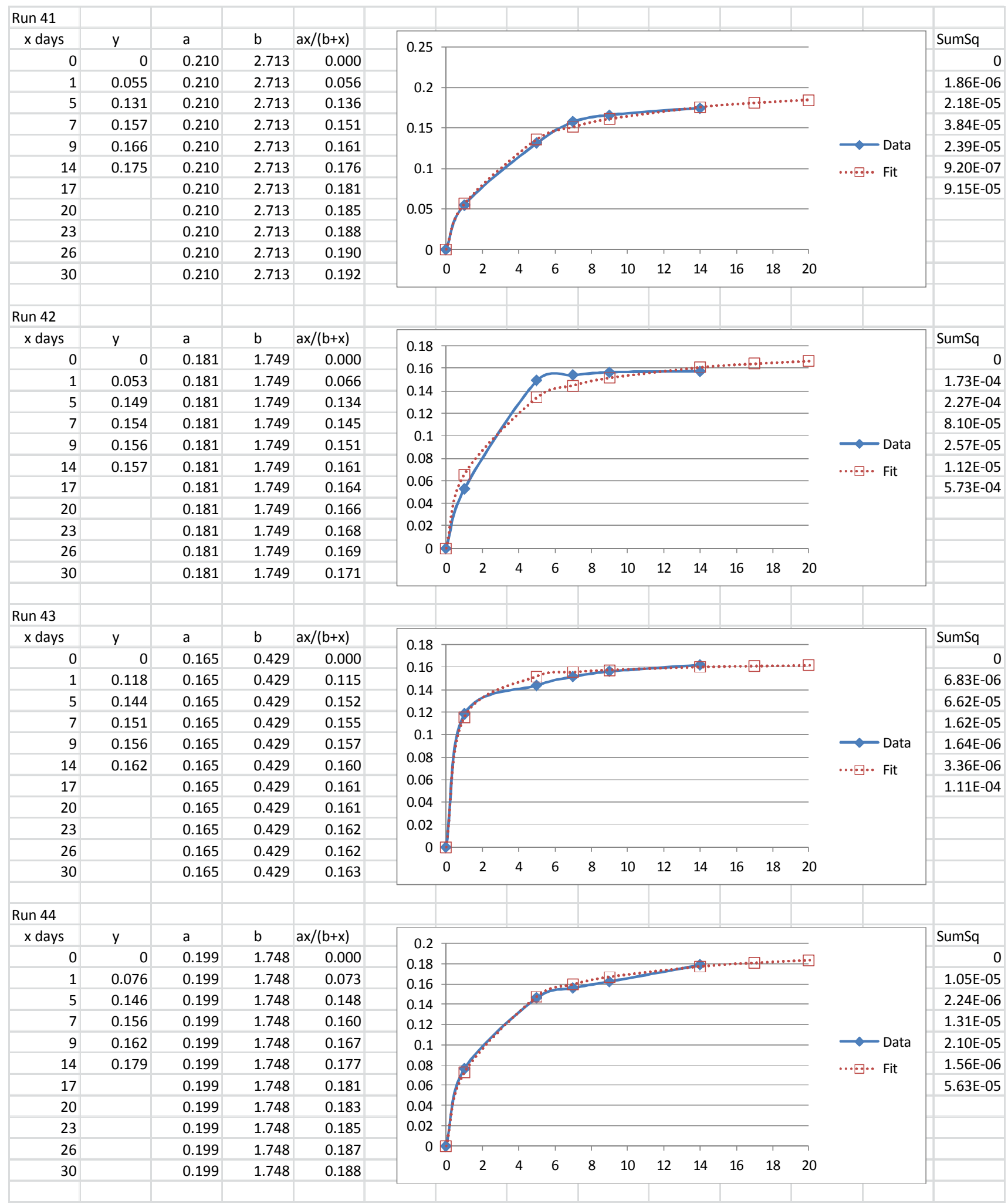


LAB-RPT-13-00011 Rev 0

Appendix B

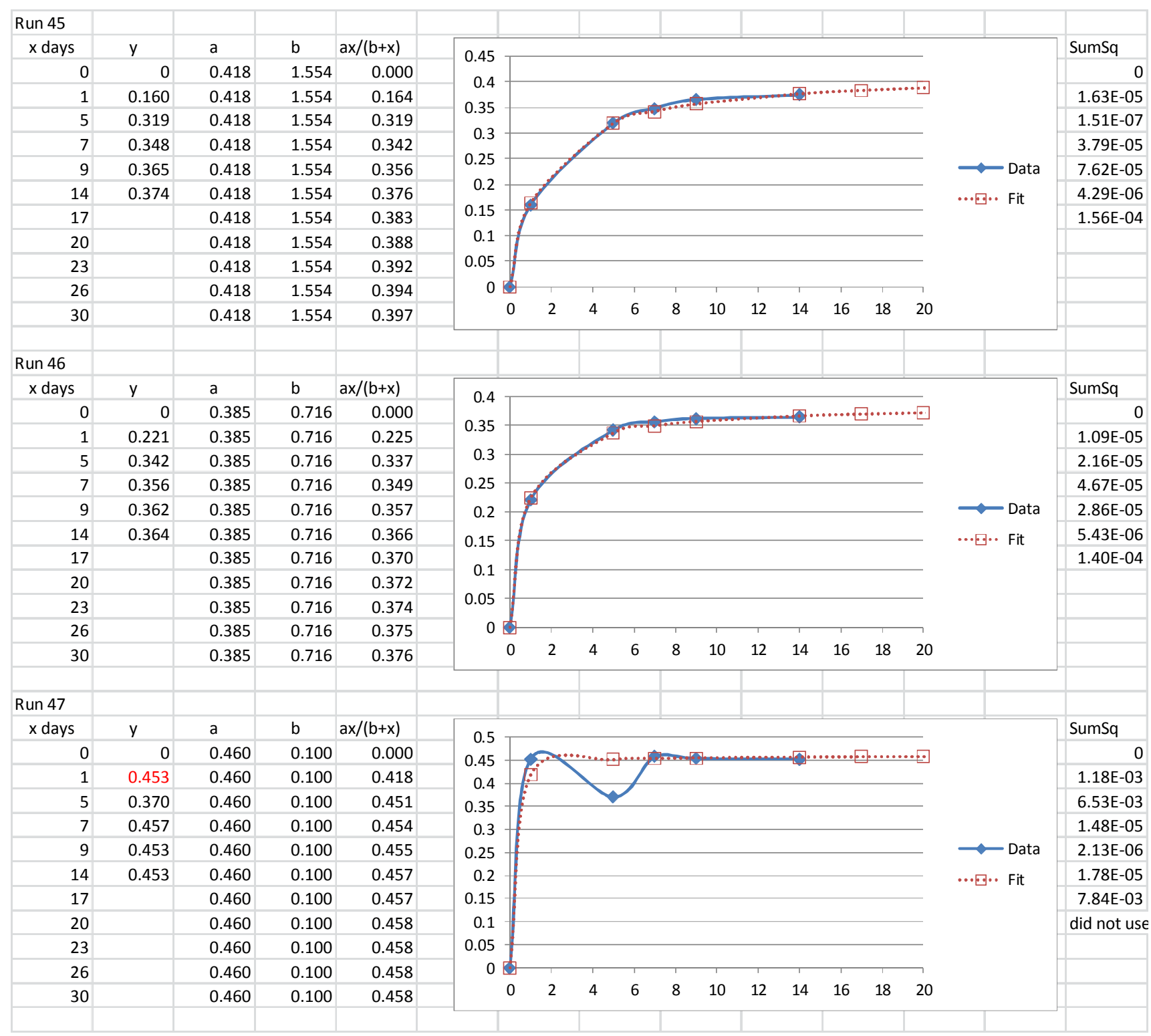




\section{Electronically Approved by:}

UserName: Herting, Daniel (h0004821)

Title: APD Chemist

Date: Monday, 13 January 2014, 11:48 AM Pacific Time

Meaning: Approved by the author or delegate

UserName: Reynolds, Jacob (h0046545)

Title:

Date: Wednesday, 15 January 2014, 07:22 AM Pacific Time

Meaning: Approved by the customer or delegate

=ニ=ニ=ニ=ニ=ニ=ニ=ニ=ニ=ニ=ニ=ニ=ニ=ニ=ニ=ニ=ニ=ニ=ニ=ニ=ニ=ニ=ニ=

UserName: Cooke, Gary (h0410221)

Title: APD Chemist

Date: Wednesday, 15 January 2014, 07:36 AM Pacific Time

Meaning: Approved by the Group Manager or delegate 
Distribution List

$\begin{array}{ll}\text { W. B. Barton } & \text { S7-90 } \\ \text { G. A. Cooke } & \text { T6-05 } \\ \text { Q. D. Ho } & \text { H4-02 } \\ \text { H. J. Huber } & \text { T6-05 } \\ \text { J. K. McCoskey } & \text { T6-05 } \\ \text { J. S. Page } & \text { T6-05 } \\ \text { J. A. Pestovich } & \text { T6-05 } \\ \text { K. L. Pierson } & \text { H4-02 } \\ \text { J. H. Rasmussen } & \text { R2-58 } \\ \text { J. G. Reynolds } & \text { R2-58 } \\ \text { L. M. Sasaki } & \text { S7-90 } \\ \text { C. M. Seidel } & \text { T6-14 } \\ \text { J. E. Trechter } & \text { T6-05 }\end{array}$

